ETNOLOGIA

\title{
Marco Geográfico del Area Cultural del "KAUKE" en el Perú (")
}

El Instituto de Einolixyía de la Faciltad de Letras de la Universidad Nacional Mayor de San Marcos, está actualmente llevando a cabo una investigación etnológica en la Cornunidad de Tupe, centro del área culiural de! idioma "Kauke" en el Perú, situada en la Provincia de Yauyos, ai Sur-Éste del depariamento de Lima.

La Etnología, ciencia reciente, ofrece un campo de acción interesantísimo en nuestro país. Su estudio tiende a conocer la obra del hombre, investigar exhcustivamente lodo lo que él hace y crea para satisfacer sus necesidades tanto materiales. conc espirituales. Toda la obra del hombre, es Thácer y craar no es sing Cultura. Por eso la Etnología es la ciancia de la Cultura. Y el único capaz de hacer cultura es el hornbre, y desde ese puntoldelvistalaVtrolósia es el estudio del hombre.

Los estudios etnolog̣icos en el Perú sstán siendo orientados al conocimiento de las Comunidades y pueblos que participan más de la Cultura aborigen que de la alienígena, pero ésto, por qué?

Según datos del Censo de 1940 existen cerca de 60.000 centros poblados en los cuales se encuenira distribuída la población en el Perú. Tomamos únicamente este dato, sin considerar errores, población dispersa, elc. En esos centros poblacios hay diferentes niveles de cultura, desde los más acielantados y réinados como en Lima y aigunas capitales de departamento, hasta los más ínfimos en la selva peruana.

(*) En la Revista "Miar del Sur" N" 11 aparecerá un relato de la Fiesta de la Herranza en Tupe. 
Podemos agrupa: estos centros posinsas en tres grandes categonas o escalcres:
a) $\operatorname{riuy~"əcil!!iridos"~}$
b) mestizos
c) indigenas: andinos
selvò̀tic-s

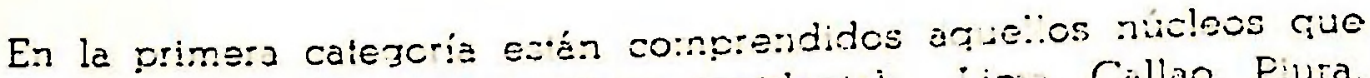
participan activamente sंe la cullura orsicientai: Lina. Cüllao, Fiura, ete. En la segunda, mestiza, agrupamos a aque..'os pieblos de cultura en transicićn, muy numerosa y fuerte en el Perú, participan de la cultura occidental y de la aborigen: Virú, Huancayo, Mocho, Tingo María, Lunahuaná, Tupe, etc., pueviss o orillas del mas, dítinas capitales de departamento, como Huancavelica, eic. En la últirna calegoría estarían comprendidas las Comunidacias indigenas, en número de más de 5.000, los caseríos desparramados en la rejich andina y todos los grupos que viven en nuestra selva.

Dentro de estas tres categorias unos puebios estarán más cercanos al grupo aculturado $\circ$ al indígena, existe una serie de variantes entre unos y otros, no hay rigidez, pero sí podemos distinguir estos grandes grupos culturalmente.

Para el etnólogo, ol estuaic de cada una de estas aprupaciones humanis es interesantecyt cualquiera decellas es su centro de trabajo. en todas puede desarrollar sus métodos y técnicas. Podemos estudiar tanto Lima como una Comunidad del Cuzco o una tribu de la selva, llegando a conclusiones interesanies para el panorama cultural del $\mathrm{Pe}$ rú y aún para el Universal. Pero, como bien lo dice Kluckhohn, nos vemos obligados a dar preferencia al estudio de los pueblos más apartados, aquellos que conservan todavía rasgos propios antiguos, rezagos de formas de vida primitiva, por el temor de que pronto desaparezcan, de que sean absorbidos por la cultura actual, con la llegada del camino, de la radio, elc., porque ya sabemos el tremendo poder que tiene la difusión cultural, la que hace olvidar o cambiar sus costumbres, creencias, funcionamiento de inslituciones, etc. De ahí la necesidad de estudiarlos prontamente. Este es el camino que han escogido los antropólogos en todo el mundo y del cual no podemos excluírnos, debido a que esta necesidad es aún más imepricsa entre nosotros.

Es urgente el estudio de las Comunidades, pueblos, mestizos que participan de la cultura antigua del Perú y de las tribus de la selva peruana, debido a: 
1.--Porque del estudio de cómo vive una comunidad andina, o selvática, del concimiento que de ella codemos tener por medio de la investigación etnolbgica, nos permitirá croyectar ese conocimienio al PASADO, lo cual nos aclarará la sornerension de muchos elementos culturales ar.tiglios, $d e$ instituciones pretéritas, tan difíciles de interpretar por la carencia de fuenies escritas.

2.-La proyezción de la investigación etnológica al FUTURO, porque la ETNOLOGIA no es estática, todo lo contrario dinámica, y solamente par ei conosimiento certero, científico del funcionamiento aciual de los grupos humizios eiı Comunidades y pueblos del Perú que participan de la Cullura Aniligua y los que están en pleno mestizaje, podremos piantear normas, directivas, estudios capitales para la verdadera orientacićn, sentido y valoración de lo que significa el proceso de "transculturación" en que vivimos. Trałamos de conocer cómo vive el hombre en el Perú, para así looder presentar bases sólidas para cualquier planeamiento futuro. Es un deber do las generaciones actuales afrontar valientemente este problema, porque de su solución depende la vida futura del pais. Bajo la grúa científica de un hombre que ha dedicado su vida a conocer la Cultura Ántigua del Perú y estudiar ese proceso de "aculturación", es que el Instituto de Etnolcgía inicia con las promociones de alumnos que va formando una serie de estudios cardinales sobre la vida del poblador indigena yomestizo delePerú. Esta labor ardua y penosa recesita ge perscnas preparadas $r$ de considerables recursos económicos y de la colaboración científica en las diferentes ramas del saber humano. Sólo un trabajo en equipo, bajo estas condiciones, presentará un verdadero panorama de cómo vive el hombre en el Perú y ello nos servirá para aplicar sus resultados a conseguir un sentido certero en la marcha de la Cultura Peruana.

3.-Nos permitirá contribuir al patrimonio universal de la cultura. A. aportar los resutados de nuestros trabajos al conosimiento cada vez más amplio y sin prejuicios de lo que es el hombre.

\section{SITUACION.-}

Podemos afirmar, desde ahora, que la única área cultural perfectamente delimitada y caracterizada en el Perú es la del "kauke' o "Jakaro", uno de los antiguos idiomas que supervive y que difiere del keshwa y aymará. El aislamiento, debido, en parte, a su configuración geográfica, ha permitido la subsistencia de ese antiguo idioma, y de una forma de vida propia, lo cual hace de sus habitantes, cerca de 1.000, ut grupo homogéneo, culturalmente mestizo, cor: piedominio indio. 
PROVINCIA DE YAUYOS

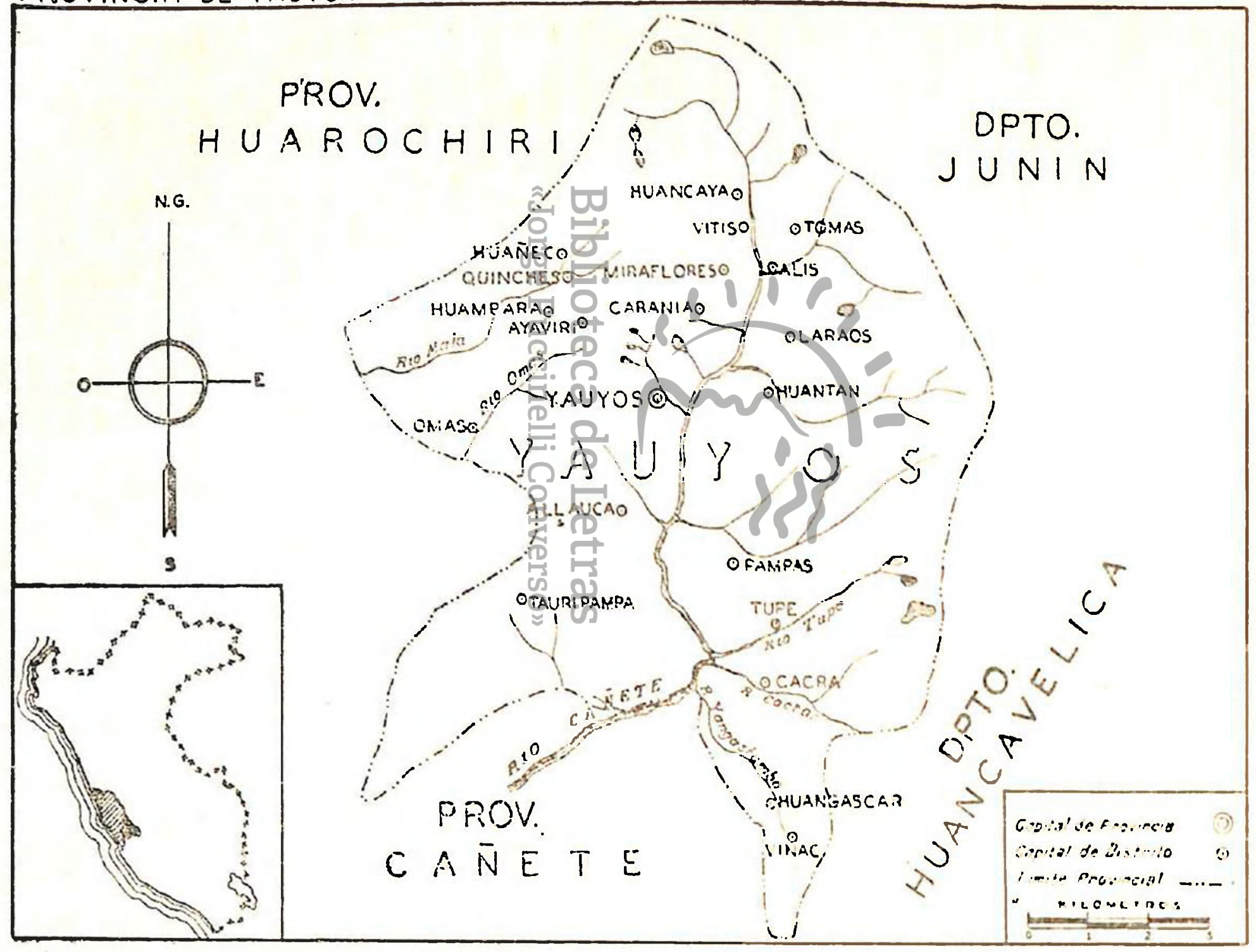


Probablemente la extensión de esta área fué mayor dur..nte el siJlo pasado, comprendiendo parte de las provincias de Canta y Huarochirí y otros sectores de Yauycs. Ahora está reducida a un distrito de esta última Provincia, el Distrito de "Lérida", nombre nuevo dado e: 1936 por extraños notivos. Pero siempre ha sido y es conocido con el noini:e de Tupe y sus moradoras y vecinos continúan llamándolo asi. Dicho Distrito comprende tres Comunidades: las de Tupe, Catahuasi y Cachuy.

\section{LA RUTA.-}

El viaje al pueblo de Tupe se hace desde Lima en dos días. Por la carretera panamericana, sección sur, el viaje es hasta el km. 1651/2, plieblo de Innerial, en la Provincia de Cañete. En este pueblo se toma el desvío hacia el lado este, carretera a Yauyos, que cruza todo el valle alto del río Cañele, vasando por los centros poblados de "El Uno", "Las Encañadas", Caltopa, Socsi (puente), Inkawasi, Paullo, San Jerónimo, Jangla, Jita, Lunahuaná, Condoray, Uchupampa, Jacaita, Catapaya (puente), Romaní, Facarán, Zúríiga, Machiuanga, San Juan, Llangas, Huaillampe, San Jerónino y Catahuasi, total unos $80 \mathrm{~km}$., desde Imperial.

Es intaresanta cheervat, en todo este recorrido, la evolución de los cultivos: en la parte tóa del valle, ptedomina el algodón y a medida que se aş̧iende poinienza la vid dando por origen la formación de conglomerados humanos dedicados a si cuidado y eláboración, de tal mocio que desde el puente da Socsi la vid deiermina una forma típica de vida en este valle: todo gira en torno de aquella, especialmente en sus centros principales como Lunahuaná y Pacarán. Se ha iniciado una investigación etnológica en Lunahuaná, donde se ha instalado un camparnento permanente. La Smithsonian Institution de Washington, el Institulo de Estudios Etnológicos del Museo de la Cultura y el Instituto de Etnología de esta Faculiad realizan este trabajo de campo.

Asimismo, es interesanle el recorrido para el arqueślogo, debido a que en ambas márgenes del valle existen magnificas ruinas, especialmente en Inkawasi y Paullu. También se observan maravillosas andenerías y canales de riego de los antiguos pobladores del valle, que nos indican su mayor utilización, ein tiempos pretéritos.

El valle de Cañete fué conocido en la antigüedad peruana como el Valle del Guarco, así Cabello Balboa, en "Miscelánea Antártica", dice que su conquista fué muy difícil para los Incas, que le pusieron el nombre de Guarco que quiere decir el "Colgadero", como recuerdo 
de la Horca que mandó levantar el inca Tupac Yupanqui. Gut-iluso dice que este valle era conccido coms de Runanuánac ("dunde el llombre escarmienta") $y$ en su parte a!:a como "Hiarm." do:lde habla hus de 30.000 vecinos y cuyo iefe era Chidrimanzu (65 T. II) el cus! les opu-

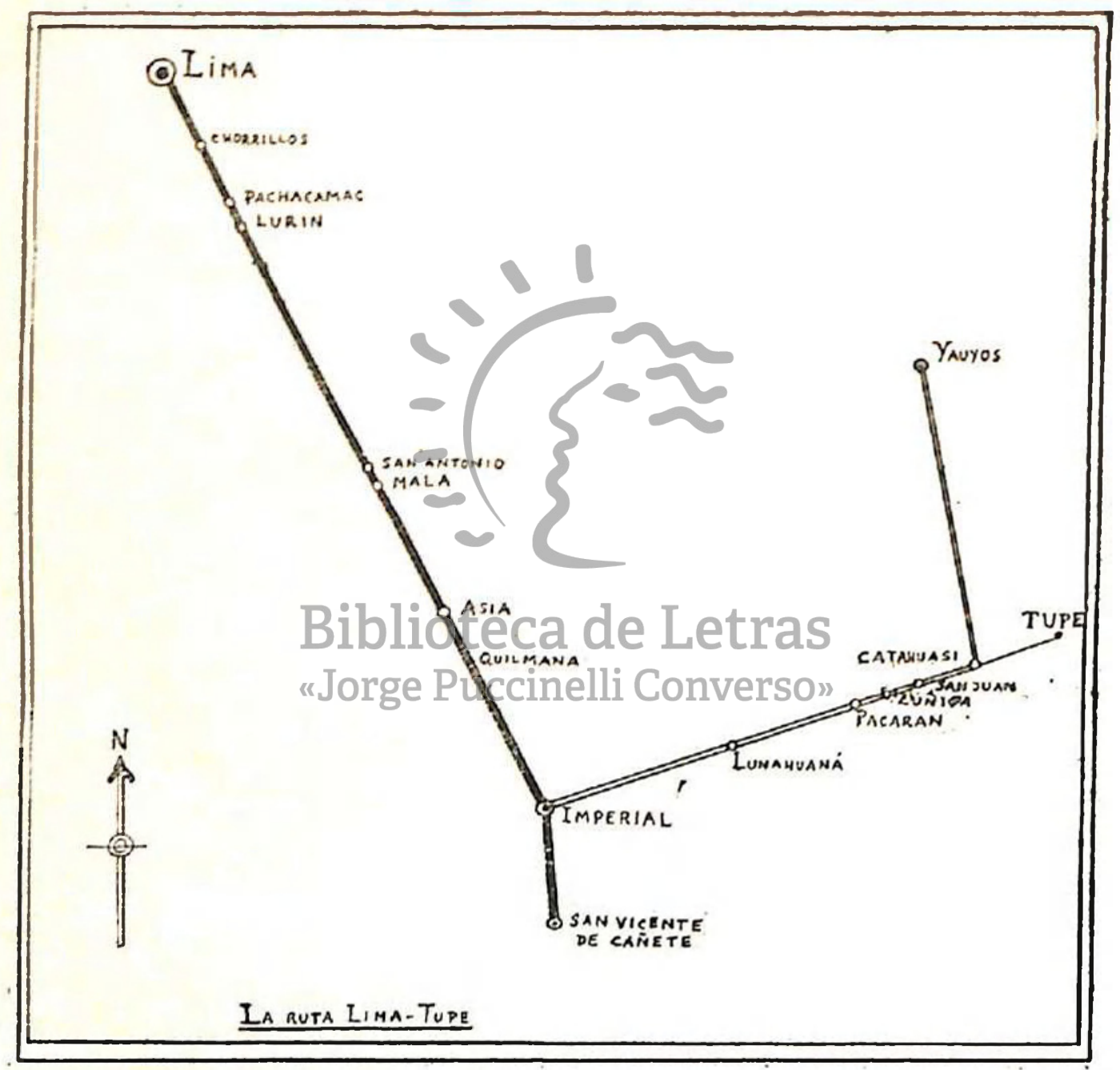

so mucha resislencia y duró su conquista 4 años $y$, al término de ella, el general Capac Yupanđui, hermano del Inca Pachacútec, "mandó hazer en el valle una fortaleza, pequeña de sitio, empero grande y maravillosa en la obra" (67 id.).

Los pueblos de Lunahuaná, Pacarán, Zúríiga y San Juan son centros importantes para nuestro estudio, porçue ellos han sido y son lugares de abastecirniento e intercambio con el pueblo de TUPE. Anti- 
guamenie los tupinos "baiaban a la costa", como ellos dicen, llevando sus quesos y papas, amén de su ganado, para cambiarlos con frutas y licores. Eran in:y quer:dos y codiciados por lodos los vecinos, tratando lodos de atenclerios lo meior posible para realizar sus negocios comerciales. Esio no solamente sucedía con los tupinos siro con los habitanies de todos los pueblos a.tos del valle de Cañate, lo chal ocurre hasta hoy. Durante los meses de Febrero a Mayo, vemos en las calles de estos pueblos a los "puneros" con sus llamas cargadas para hacer sus intercambics. Constituye así el mercatio número uno de todos los pueblos situados al iado sureste, expecialmente del valle, tales como: Cacra, Viñac, Huanğsscar, Tupe, Pampas, Laraos y Huantán y todos sus anexos. La carretera ha contribuido a afianzar más esta comercio. Por otra parte, los unahuaneros, pacaraneros, etc., más ccnocidos como costaños o "chaplass" o yunginos, (de chapana o yunga), viajan a menudo a todos escs pueblos llevando sis productos.

\section{LA COMUNIDAD DE CATEHUASI-}

Catahuasi corresponde ya al Distrito de Tupe, es una de sus comunidacies. Tiene según el censo de 1940, 222 habitantes. Su nombre significa "casa de manias". Tiempo atrás, era conocido ca: el nombre de "W "WHIOKO", los tupinos lodavía lo llaman asi, es un pueblo muy antiguo: lo encontramos menconadolen la visita de Tor:'s de Mogrovejo, en documentos de los siqlos XVIIIY XVIII quesse e:cuentran en el Archivo Arzopispal

Para completar la gradiente cuitural, otro de los espectos de nuestro estudio etnolégico, también hemos instalado otro cempamento de trabajo en esta Cominidad, a cargo de lin alumno egresajo del instituto, de esta manera podremos conocer el cambio cultural en sentido transversal en una zona del país, el valle de Cañete, esperando comp'etarlo con el estudio de un puéblo de la parte baja del vall z: Cerro Azul, San Vicente o San Luis. A. finalizar, podremos tener una idea de las diferentes formas de vi.2ia de los habitantes de un valle costeño desde la orilla del mar hasta la Puna (ảe Tupe), conectando este estudio con el que se ha hecho en el val!e de! Mantaro, en Sicaya y Muquiyauyo, el primero por el Instituto de Estudios Etnolćgicos y el segundo por un alumno egresado de la Universijad de Yale y luego con el reconocimiento del Sátipo, un pueblo de ceja de selva, que se ha realizado con alumnos del Instit to de Elnolcgía baio la dirección del profesar Jehan Ve!lard. Así queżarán conectadas las tres grandes reg:cres: Costa. Sie$r=$ y l.contaña, e.? una investigación etnoíćgica de gran trascendencia. 
La Comuntdad de Caiahuasi está dividita en cuâtro centros poblados: el PUEELO, la COMUNIDA.D. TAMiBO y CANCHARj GRANDE. La Co:suindad apenas tierie unos 20 añss de existencia, inarcada por la cparición de la carretera, igual ciue Canchán y Tamio. E! Pueblo está ubicado en la parie alta de ies cont:afueries de la cordillera occidental y el el cunino a Tups, distà unos a dince minutes a pie desta da carretera. el camino es bastäı ditidit. lifientras cue la carreterà está situada a unos 1.300 meicos sobre el nivel de! mar, $€$ l pueblo lo está a unos $1.450 \mathrm{~m}$.

Actuaimente se presentá un ́enómeno curioso: e'. Plieblo está trasladíndose a la parto baja, la Conuridiad, deibico a su acceso a la carretea. Is un caso de atraczión de ia car:eiera Los irabajos se encuentran bastante adelantaios debido a que son muy enprende lores: en menos de un año han levantedo e! nievo :oca! para la Guardia Civil, la Escuela, Cficina de Telógriclos y los principales vesinos eztín constru-

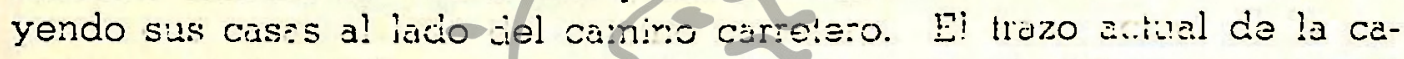
rreie:a sora desvidido un p=co hacia e! lacio izmuierdo (îo:te) y es muy probabie que àntro de verios años tenclremos situedo Caizhuasi a la vera del nuevo camino.

En la COMTIIIDAD existe: unas s:eie casas, dos restaurantes y el Puesto Viejo de lä Gulärdie Givi!, docias Ejas hechas cie carizo o quincha y adobes, algunas entucidis con cal.

LI PÜBLO, "shrado encha parle alk GeSQHa pendiente, tiene una plaza de reguler extensión, lo suficientemonte grande para que en eila se desarrolien campeonatos de foct-bäll, à los quie concurren equipos de todos los pusblos ves:ncs. En d:cha Piaza, tienen lugar preeminente

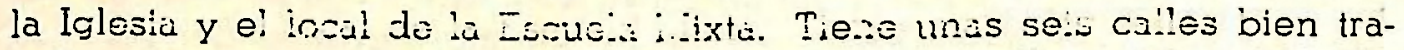
zadas. La principa! es por clonde pasa el camino a Turs.s. Entre la Comunidad y el Pueblo exisien varias casas. Estas son de una o dos piezas, bastante orandes y de adobes, paredes pintadas al temple, techos de barro y carrizo y a!gunas de ca'amina a dos aguas.

La Comunijad de Catahuasi es fámcsa por su gran producción de limones y paitas. Tombién hôy naranjas, quayabas y manúcs, así como yucas, algodón y alfalfa. Los limones ea época de abundancia se venden de 0.50 centavos a 5 l.00 el enento. Ias pạltas, en igual época, febrero a abril, cie 20 a $\cong 0$ soles e! ciento. La producción de limones es tccio el año.

En la parie de Catahuasi y en una aitiplanic:e extensa entre las faidas de los cerros de Tupe y Cachuy existe la pampa de Cairán que ha permanecido sin cultivar, por fáta de eguia, desde tiempos precolom- 
birios. El año pasado descubrieron el antiguo canal y se ha comen-

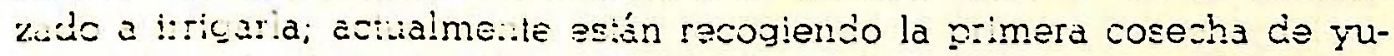

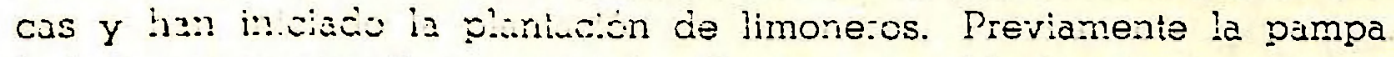
la lot:arron y repatiecca entre los Conune:cs. Muchos tupincs tienen lo:es en ella. Se caicua que la oroducción de limones pueda rendir al aiso uncs sien mil scies.

Sejún di:os de: Fuerio de la Guardia Civil, el área cuitivada es de $15 \mathrm{~km} 2$. Existe, aàentas, nucho qanado vacuno, lechero sobreiodo, sejún !a nisma fuente de intormación, hây unas l.c00 cabezas. De lana:es, urses 2.00?; hay tambij.. ganado rorenc, cabailar y mu.er. Lcros en grandes pirvadas rezo:ren toda la zona, constituyendo la principa! p'age para e! maiz. Esias àres liegan hasta e! pueblo de Tupe, amagancio las cosechas.

La maycría de los habitantes son hijos de familias tuphas; pero, a peazar de ísio, solinente unas y o 5 familias hablan el kauke o to ent:enden sin hublar.o. Cuando realicemos ol censo elnolégico en esta Comunidad sabrenos exmetamente la cani:dad de personas que habian el kaules. Piensan que hablarlo demuestra poca culiura porque ellos se consideran cozteñoz y a los tupinos los tratan como "serranos". Así es que esta Conmidai, a pesar de estar el el área geogrífica del kauke, ro partipa že su dioma.

Sus pobiadores, bistanle emprendedores, casi no concen Iupe y

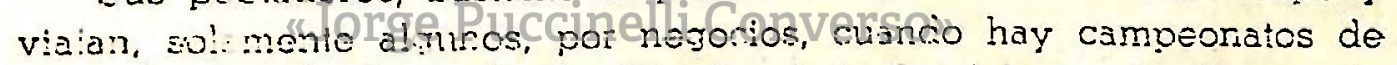
fcu-ja!! p ra la Fiesta da San Bartolomé, la Candelaria o la Feria. Su

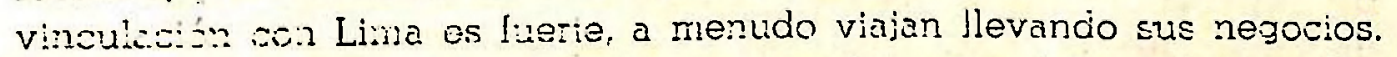
Muchci pjó.es se p-osum de que sis hijos puedan acabar su instrucción Secundaria. i.a Cumundad, per sus linteros, ha tenso michas dif eultaries con lupe. A pesar de que muchos hijos del pulebio han corcint:lo su Instrucción Secundaria, no se ha dado el caso de qua alguno dio ellocs sea Alcalde, Eobenacior c Juez de Paz del Disizito, siempre los tup nos sen los que ejacen estos cargos y los catahuasinos reconocen muchos condiciones y habilidedes en la gente de arriba los "serranos".

Cuanclo unc manifiesta que va a Tupe, la gente de! valle y especiaimento las catahiasilisi, rəsponden rápiáanente que es muy difícil y peligrcso il chí, primero por el camino, y lueso porque la gente es muir meia, no prestan facilidades a los vieieros, son "muy cerrados" porque cono nunza viajān, no saben lo quue es dar hospitalidad. Que se debe te:e: nucho cuisiado. 
De Lima a Catchnas: existe un zervis:o regulat do cmnibus de la

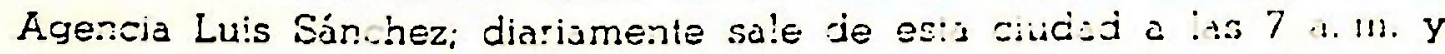
llega a las 4 o 5 p. m. En Cachuasi, la Gaurila Civil nos ha dado

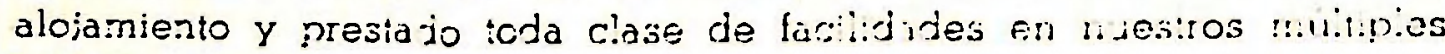
viajes.

C:MCHAN, está situado en el camino c riz:ero, a! norte de Caiahuzsi. Tiene este caserio a familias con unis 15 perconas.

\section{LA COMUNIDAL TEE TUPE.-}

Saliendo de Catahuasi miay temprano, el riaje a jupe se hace a cabalio o mula ("caba!lerías") y dura ó á 7 hor as. Lo irec ıe:te es el recorrido a pie, el rue se hoce en igual timpo. Lespućs de atruvesar el pueblo. se llega al Cementerio y de aili comienza la ascención a un cerro muy empinado lamado KLLAPSHij; se hace en zig-zag y, a paso regilar, el rezorrido dura una hora. Un thino diestro, cortúndo camino lo hace en mejia hora. La cima del cerro tiene la forma de un cuelio y Está a unos $1.600 \mathrm{~m}$. Sobre el nivel del mar, ahi existe una cruz. Desde esia cuello se contempla la Comunidad de Catahuasi muy abajo y en un plinno con el río, a un costado las pampas de Caipán, al otro lado los contrafuertes de la cordillera occidental en un plano

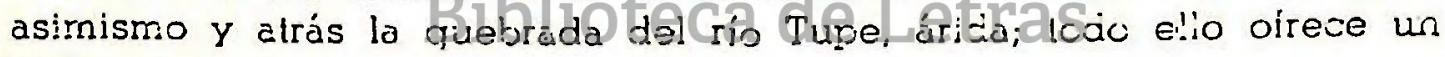
bell.o panorama.

"Jorge Puccinelli Converso"

De KALlAPSHU el camino sigue el lado izqu:erdo de la quebrada de Tupe, faldeando por la parle media del cerro, terreno rocoso, lleno de varied regreso este lugar sirve de descanso al viajero. Cuando uno está solo la inmensidad del panorama en medio de un gran silencio, lo hace pensar absorto en lo maravilloso que es la naturaleza pero, cuando está uno acompañado por un tupino, se entera de tristes recuerdos vinculados a KALLAPSHU, del odio entre dos familias, de una serie de crímenes y venganzas, de lo que para ellos significa cruzarlo, ingresar a un mundo diferente. Hasta ahí se siente seguro, dueño de si, en su lierra, ir adelante es ir a lo desconocido, todo esto como rezago de injusticias años atrás, trabajos obligatorios en la carrelera, la explotación por el mestizo del valle, la esperanza o desesperanza de un juicio en Yauyos, la explotación de las autoridades, de los funcionarios; el desprecio a los "indios" y más atrás la contribución, con toda su s’ecuela de injusticias. Triste en la inmensidad nos cuenta sus rezuerdos y penas, y nosotros lo consolamios con la esperanze de un mundo mejor. 
Ya avanzando unos minutos tenemos al lado derecho las magníficas andenerias de WI'TSH-KA y WITSH-KAPAMFA, completamente abandonadas, así conio los canales de irrigación que faldean los cerros. en diferentes direcciones. Todo lo cual nos demuestra el aprovechamiento intensivo de toda la quebrada por sus antiguos moradores, e igualmente nos da una idea de lo que es más adelante la quebrada: una zona llena de andenerías en toda su extensión; hoy solamente se aprovecha una mitad de ellas. El cultivo de la tierra en sentido vertical es la característica de la agricultura en esta quebrada.

Después de faldear durante una hora se llega al lugar llamadoMITARKIPA, doncle hay una cruz, desde este sitio se divisa ya el pueblo de Tupe. Siempre cruzando terrenos áridos, y a otra hora de viaje, está KIKRAYA, situada debajo del camino, es la primera parte verde en todo el recorrido. En este lugar, se cultiva mucha fruta: granadillas, melocotones, pacaes, naranjas, limones; y café, camotes, yucas, algodón, etc.

Paralelamente a este camino (Norte), por la otra falda de la quebrada (Sur), después del río, que corre a unos $100 \mathrm{~m}$. de profundidad, está el camino de Catahuasi-Colca-Tupe, otra ruta a esta Comunidad. Ahi están situadas las caídas de agua de WANTURU, que en época de lluvias forma cinco pequeñas cascadas. Y frente a AIZA el cerro. llamado KÁNMBANDURE (Campana Torre), lugar de ruinas arqueológicas. En la parte alta de la quebrada y ya en camino al disirito vecino de Cacra esta la antigua ciudad precolombina cuyos restos arqueológicos están baștante ôler çnsêryados centro arqueológico de la zona, es conocida como CIUDAD.

El viaje a Tupe cambia completamente de panorama en KIKRAYA; desde aquí se hace placentero, la retama que bordea perfumando todo el camino y que constituye la flor por excelencia de la quebrada, por su abundancia, ofrece un paisaje hermoso con sus flores amarillas, que se complementa con los cactus, gigantones y magueyes. Las flores de la retama son el âlimento preferido de las cabras, a las cuales vemos entre las plantas, ofreciendo un agradable espectáculo.

Para llegar al pueblo de AIZA, que es el primer centro poblado en el camino hay que ascender desde KIKRAYA la segunda subida fuerte de la ruta, KAP-KAPO, es muy peligrosa debido a que es toda pedregosa y que siempre por motivo de las lluvias o del riego es una verdadera acequia de agua. Pero su penosidad está atenuada por el magnífico verdor de las alfalfares situados a ambos lados de él. Al fondo está MUTCH-KA, una parte del pueblo de Aiza. En la parte alta Y 


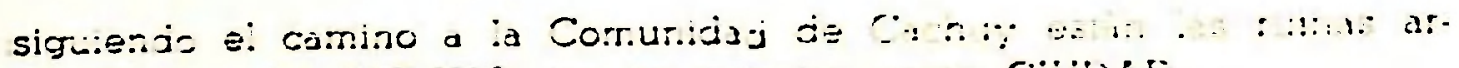

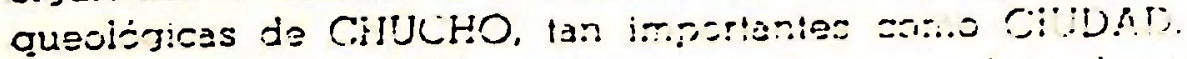

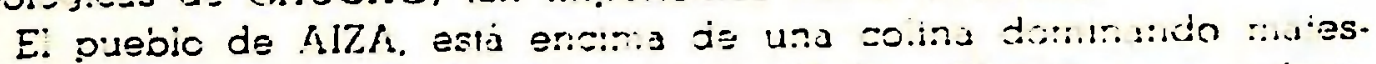

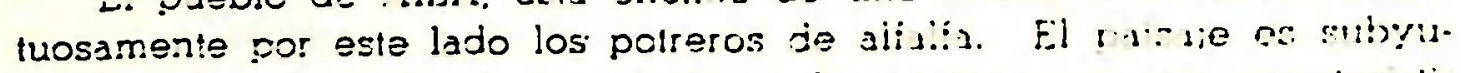
gante: entre el verdor de los a!fa!tares las tupinas con su cum

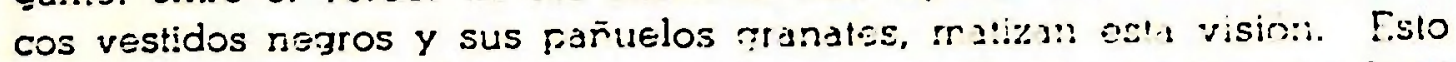
6e complementa con los niños que yan pastando siz conias o calras en las faldas de los cerros. los loros en parvadas buscari-lo o! maz. los hombres llevando el ajua de un lugar a otro y les vasas coniendo plá. cidamente la abundante alfalla que produce esin tierra $y$ tescie lo ilio. ja gente del pueblo de Áiza, mirando la liezada de los virieror.

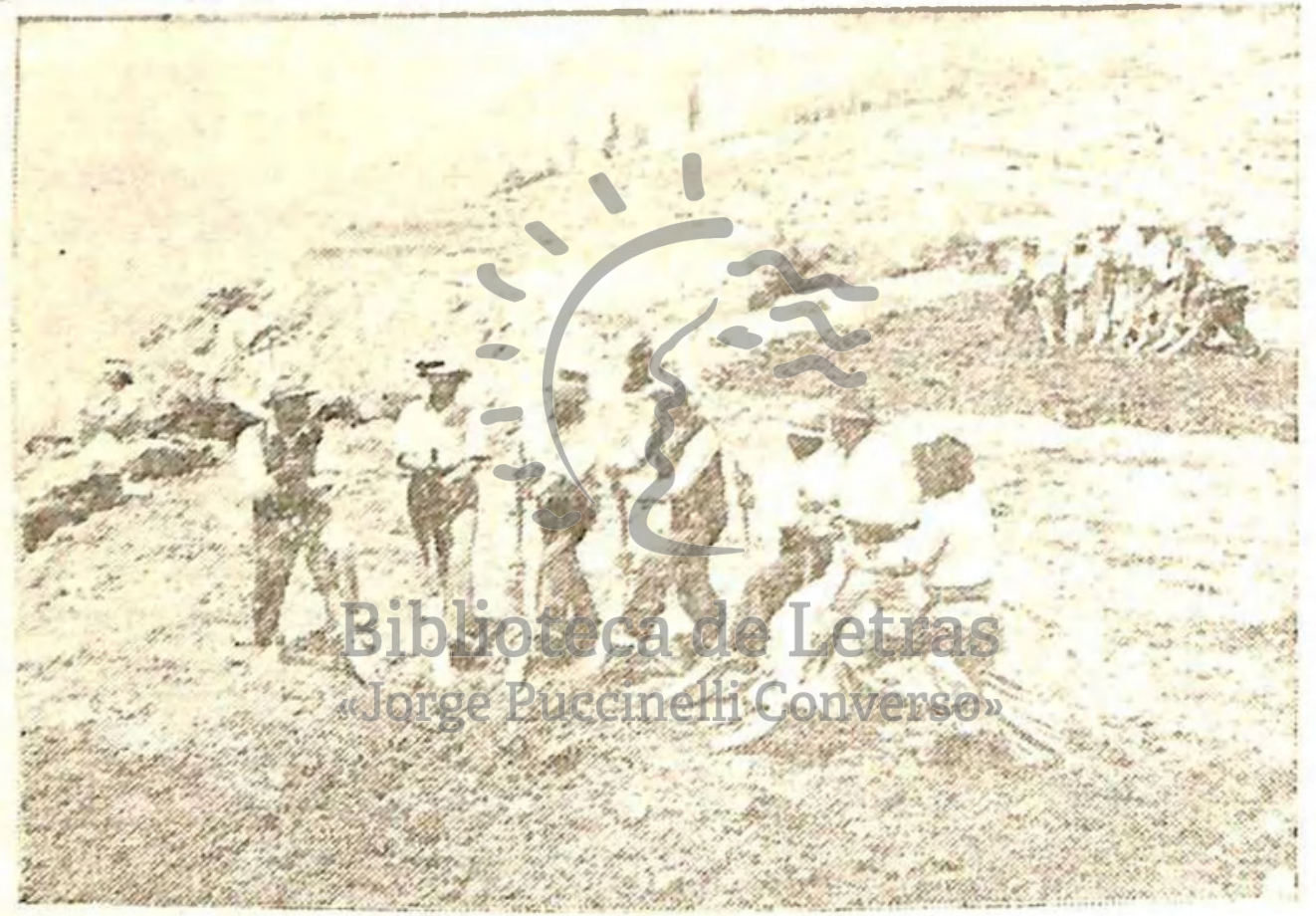

La siernbra del maíz en Riza

El pueblo es un anexo de Tupe y está dentro de la jurisdicción de su Comunidad, aquí todos hablan kauke y la maycría de ellos tienen sus casas también en Tupe o los tupinos las taren aqui. Eitis dicen que Aiza es lo mismo que Tupe, "estarnos aquí y allá". Viven actualmente sejún nuestros datos unas 59 farnilias cen un total de 90 casas. Según el censo existen $28 f$ personas (Censo de 1940).

Tiene una sola calle por donde pasa el carnino a Thipe y eslí siluado en la conjunción de varios cerros crue forman una ladera ame!la de 
l.erras ailas. Siguiendo el camino a Tupe y después de crizar las primeras casas el viajero se encuentra frente a un nuevo paisaje, completamente inesperado: las magníficas andenerías de Aiza, perfectamenio alineadas, como si f́era un dibujo, que se extiende: por cerca de $300 \mathrm{~m}$. Le largo por nunos 500 a $600 \mathrm{~m}$. de ancho. Durante los meses

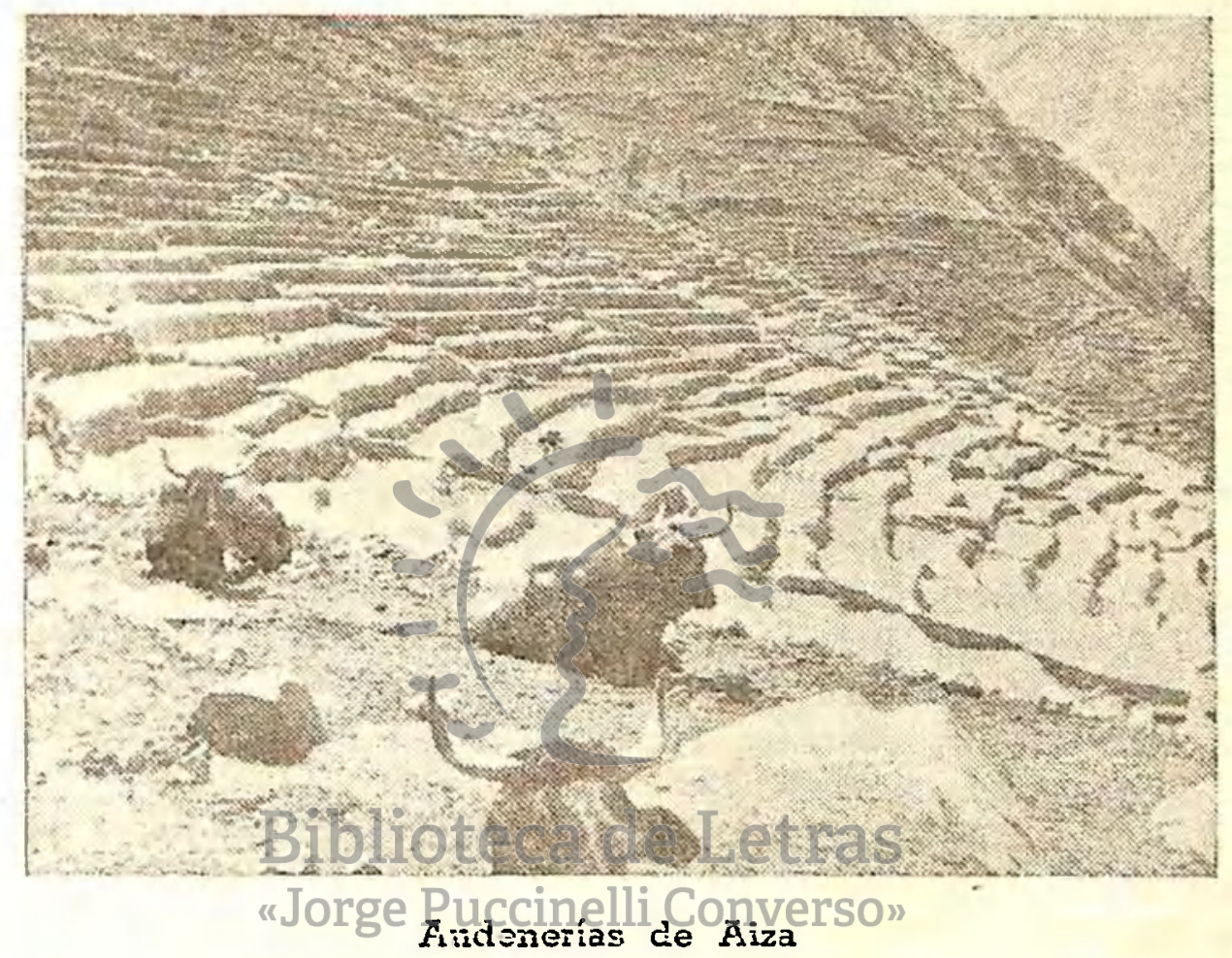

de felbrero a julio esiá cultivado con maíz KANTA (amarillo). WAXARA KANTA. Su siembra constituye un acontecimiento en la quebrada, participando en ella todos sus habitantes. En medio de gran buliicio, coheies, jarawis, "mingas" o "turna" (formas de trabajo), combinan el trabajo individual con el colectivo, admirablemenle. Todos los habitantes de la quebrada (Tupe, Aiza, Colca) tienen su porción de andenes propiedad individual, pero, para la siembra, que dura una semana, todo es colectivo, se comienza en un día determinado, unos a otros se ayudan, se hacen atenciones entre ellos y lo interesante es la siembra propiamente dicha, los hombres acomodados uno al costado del otro, en grupos de 4 a 10. y en semicírcilo, aran los andenes con su TAKLLAS, con un sincronismo perfectc, mientras que las mujeres van poniendo las semillas en la tierra. Uno de los espectáculos de mayor belleza que 
todav'a se pueden presenciar en el Pe:ú. En lullo se huc la osecha y en la úlitima semana tojo el ganodo de la zona es in!:ociu.to do on los anderes para que coma las "cha:as", a esio le tianta: e. "ustr o to tois chalères" que dura 405 dias. En julio de 1949 en un dila comantus la:as 3.000 cabezas de ganado. De julio a set:embre permaneren en "blanco" los codenes, lo cual le da otra fisonomia. En settemire, comincua le siembra ds paja que es coscsiaja en exere.

E! pueblo de Aiza con sus casas y andenes tiene varius divisiones: 1.-A:za C:uz: la parle cóniti:a dende estén las casas.

2.-Aiza p:mpa o AISF-PAMPA, la parte baja de los andenzs.

3.-NAS-KOTRA, encima $¿ \therefore$ Aiza C:uz, al lado Este.

4.-ARKAINHA, encima de Aiza Ciuz, por e! Norte.

5.-SHUNKO, encima de Arráisha.

6.-MUTCH-KA (morterci ai lado noroeste del pué̀.o.

7.-WILLKAJA (quebrada chica), al lado Este del caserio.

8.-MISKALA (piedra mesa) en el Camino a Tupe, hacia e! Este.

Aiza, desde poro tiempo atrás, está tomando bastante auge y se nota ya la formación de un puéslo que tiene algunas caracteristicas que difieren de Tupe, su manera de vivir varía en algo. Pantes era un câserio, ahora es un puebio. Su genle viaja más a la costa y cada día tratan de hacerse más independientes de Tupe.

Del cuello de KALAPSTE G2A. Ra hay uñas 3 a 4 horas de viaje Después de rezorrer todos los andenes en su parte céntrica, se llega a WILIKAJA, una de las divisiones del pueblo, donde hay una casa con 5 personas y luego a MISK $A$ IA, a unos 15 minutos de Aiza. Ahi existen 4 casas con 21 habitantes. De Aiza a Tupe todas las faldas de las cerros de arriba a abaio son andenerías cultivadas, especialmente de maíz, papa, trigo, cebada. Los andenes de una determinada zona se siembran por rotación, un año maiz, otro papa. También un año se siemiora una zona $\mathrm{y}$ al año siguiente la ctra.

Al otro lado del río y frente a Aizas está COLCA, otro pueblo de la Comunidad, donde existen 10 casas con 7 familias y 35 personas. A su lado este, está CJY $A_{1}$, una parte de Colca, donde hay 15 casas con 13 familias y 51 persorias.Estos dos pueblos están situados en andenería y sus casas están dispersas.

Después de pasar MISKALA, a unos 20 minutos se encuentra otro caserío, WITSHKA, ya jurisdicción del mismo Tupe, con 12 casas donde viven 9 familias con 32 personas. 
De este lugar se pasa a WAIKACHA ṇue es otra cuesta dificil, se se recorre en 20 minutos y Luejo ya está el viajero a lá fálüss del cerro tutelar del puen!o: TUPINACHAKA (Tupe Viejo). En la parte baja del camino esté KAPIÁ, marnníficos andenes y luego el río Chancay a la entrâda del pueblo, cruzándolo por un puenie llamado WILAKANKA, este rio baja de los nevados de KURIVILKA situados al lado Noreste del pueblo en plena puna. En esta puente el camino se bifurca en dos ramites, uno por la parte alta que va a la Plaza Prinzipsil y el otro por la parte baja va al barrio llamado Malambo.

Tupe está situado en la carie al’a de la conjunción de dos ríos: el CHANCAY y el KCTCHAPAYA, teniendo a un lido el cerro PUPRE $y$ al otro el TUPINACHIKKA. Es zona bastante áspera y pedregosa, sus casas están construídas en la pequeña quebrada de tie:ras a.tas que forma el río Chancay. Su declive bastante fuerte es de unos $200 \mathrm{~m}$.

Atravesando el pueblo, sigue el camino, hasia la Puna de Tupa, a la que se liega en un día y su extensión es encrine; siendo una zona de pastos naturales, que son de propiedad de la Comunidad y que anualmente se arriendan por sectures, llamados "paraderos", a los comuneros de Tups; es un centro ganadero astuslmente en formación. Los tupinos han comenzade a criar ganado apenas desde hace unes 15 años. La riqueza de esta puna en auquéniclos es cuantiosa. Las vicuñas son muy abundantes debido a que no se les mclesta. Viven unas 20 familias tupinas y 2 fanilias(de fuera una defPampas y otra de Huantán) con cerca de 80 perscans. Putas familias tupinas tiennen sus casas también en el puejlo. Del pueblo, por esta direcaión que lleva a Huancayo, al límite de la jurisdicción del Distrito que, a su vez, lo es de la Comunidad, hay dos días de viaje.

\section{LA COMUNIDAD DE C:ACHUY.-}

La siguiente quebrada al lado Norte de Tupe se llama :CHIÚRE, donde existe un pequeño caserío que tiene el mismo nombre, àhí viven 5 familias con 30 personas. Este centro poblado se halla en el camino de Tupe a Cachuy. El río, que nace en los nevados de KURIVILKA, parte llamada KAPATOMA, tiene el mismo nombre :CHIURE.

Cachuy está situado en la cima norte de la quebrada y constituye este pueblo la tercera Comunidad dentro del Distrito, es famoso en todo el valle por la celebración anual de la festividad de la Milagrasa Aparición del Serior de la Ascensión de Cachuy. Tiene dos anexos: ambos situados en la carretera a Yauyos: CANCHAN (en su parte derecha) y CHAVIN. Anualmente para la referida fiesta religiosa, en el 
mes de Mayo, cracurren miles de peregrincs y lo curcoso es que el adventismo ha ganado a casi todos sus habitinies, corrincio la celebración de la fiesta a cargo de personas de íle:a. Tiene una mainifica Igies:a, Escuela Miłta ce Prinet Grado, Agente Munctoal, Teniente Gobernador y Iuez de Paz. Los zachilinos casi no entienden el kauke a pesar de estar emparentados rnuchos de elios con los tupinos. El kauke que hablan parere ser un dialerto de! de Tupe. El puebio está ubicado en lá parte alta de un cerro, a unos 3,000 m. sobre el nivel del mar. De CAINCIAN e! viaie se hace en unas 6 horas a caballo $y$ el regreso en 1 hora a piś, ror ser una subida nuy empinada.

LiMílTES. - El área del kauke en el Perú t:ene por línites los mismos de su dernarcazićn nolítice conjo Distrito.

Por el Sur: Cacra.

Por a! Norte: Pampas.

Por el Este: Huancayo y Huanzavelica.

Por el Oeste: el río Cañete.

SUPERFICIE: El Perú tiene l'249,049 Km2. E'l Departámento de Lima, $33,984 \mathrm{~km} 2$. La provincia de Yauyos $8,344 \mathrm{~km} 2$. y el distrito de Tupe, aproximadament = unos $250 \mathrm{~km} 2$.

ALTURA: La zorad diene diferentes jalturas Catahuasi la menor, 1,300 m. sobre el nivel del mar.

Tupe es la intermedia: a $2,830 \mathrm{~m}$. sobre el nivel del mar.

La Puna eníre unos 3,200 a $4,200 \mathrm{~m}$.

IONGITUD Y LATITUD: Indico la del pueblo de Tupe: Longitud $75^{\circ} 45^{\prime}$; Latitud $12^{\circ} 45^{\prime}$.

II.-DIVISION POLITIC.A._

$P_{1}$ crearse el Departamento de Lima, por Decreto Supremo de 4 de A-gosto de 1821, comprendía las Provincias de Lima, Cañete, Huarochirí y Yauyos. Así es que Yauyos existe como Provincia del Departamento de Lima, desde 1821. saber:

En la fecha el Departamento de Lima comprende 7 provincias, a

1. Lima

2. Cajatambo

3. Canta 

4. Cañeie
5. Chancay
6. Huarozhiri
7. Yauyos.

El Censo Nacional de Población de 1940, para el Departamento de Lima, publicado en 1948 (Volumen V), da los siguientes datos:

\begin{tabular}{lccccc} 
Provincias & $\begin{array}{c}\text { Distritos } \\
1948\end{array}$ & $\begin{array}{c}\text { Distritos } \\
1946\end{array}$ & $\begin{array}{c}\text { Superficie } \\
\text { Kin2. }\end{array}$ & Pobiación & $\begin{array}{c}\text { Centros } \\
\text { Poblados }\end{array}$ \\
Lima & 20 & 20 & 38.984 & 577,070 & 2,231 \\
Cajatambo & 10 & 10 & 2.604 & 23,640 & 257 \\
Canta & 10 & 9 & 4.823 & 28,670 & 349 \\
Cañete & 16 & 12 & 4.565 & 48,344 & 238 \\
Chancay & 19 & 17 & 6.598 & 103,220 & 453 \\
Huarochiri & 19 & 13 & 5.185 & 37,587 & 322 \\
Yauyos & 21 & 20 & 8.344 & 30,640 & 357 \\
\multicolumn{5}{c}{ De esto se deduce que la Provincia de Yauyos ocupa el primer }
\end{tabular}
lugar en cantidad de distritos. En superficie, el segundo, después de Lima. En población, el quinto, después de Lima, Chancay, Cañete y Huarochiri. Y el tercer lugar en cantidad de centros poblados, después de Lima y Chancay.

La Provincia de Yauvos fiene-actualmente-21 distritos y ellos son: "Jorge Puccinelli Converso"

Distritos

1. Yauyos 2.048

2. Alis 1.041

3. Allauca 1.402

4. Ayaviri 982

5. Cacra $\quad 1.822$

6. Carania 704

7. Colonia (!) 2.391

Total Cap. Distrito

Familias Familias

1.058

598

483

Cap. Dist.

Centros

8. Huampará 1.001

9. Huancaya 1.158

4.26

935

565

537

333

519

469

10. Huangascar 2.843

506

11. Huantán

1.328

1.098

12. Huañec

1.788

799

13. Laraos

1.620

14. Lérida (2)

1.366

1.023

524

244
129
104
190
129
138
69
119
106
76
295
172
259
130

Poblados

269

334

204

400

183

519

221

260

516

347

344

402

344

130

14

19

19

11

12

2

15

14

11

46

19

4

46

8 


\begin{tabular}{|c|c|c|c|c|c|}
\hline Distritos & $\begin{array}{c}\text { Po:jlacien } \\
\text { Toial }\end{array}$ & $\begin{array}{l}\text { Pob.a-: } \\
\text { Cap. L:s:a:oo }\end{array}$ & $\begin{array}{l}5 \ldots \\
\text { Dan }\end{array}$ & $\begin{array}{lll}\square & \cdots \\
\alpha & \end{array}$ & $\begin{array}{l}C \because \ldots: 0 S \\
\square \quad: \text { iss }\end{array}$ \\
\hline 15. Miralores & 757 & 455 & $18 \div$ & 114 & i \\
\hline 16. Omas & 1.625 & $27 ?$ & 324 & 54 & 24 \\
\hline 17. Quinches & 1.210 & 1.5. $0_{2} 4$ & $3: 4$ & 200 & 7 \\
\hline 18. Tauripampa & 1.004 & s.Sก & $: \vartheta \hat{c}$ & 115 & 5 \\
\hline 19. Tomas & 1.908 & 470 & $2 ; 9$ & 99 & 53 \\
\hline 20. Viñac & 2.089 & $8 ! / 4$ & 801 & 1.45 & 35 \\
\hline 21. Vitis (3) & - & - & - - & $\cdots$ & $\cdots$ \\
\hline
\end{tabular}

(1) Parnpas; (2) TUPE; (3) Sir cintos per haber sids creacio en 194.4

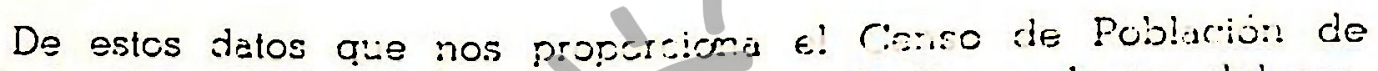
1940, se deduce lo siguiente chie el Distrito cie Tupe, dentro de! resto de los distritos de la provincia czural en poblazira el undécimo lugar; en población por capicales de cisistrto, el jếc:ino lugar; en número de familias por distritos, el noveno lugar, por caritales de distrito, el noveno lugar y en rúmero de centros poblados al décimo quinto lugar.

En el distrito de Tupe, exisien tres] co:munidades reconocidàs:

1. La Comunided de Tubs, con sus certros poblados. Aiza, Colca, Cuya, WITSHKA, CHqUREGWANTURO, liANCHIKESQ Puna de Tupe.

2. La Comunidad de Cachuy, con sus anexos: Chavin y Canchán.

3. La Comunidad de Catahuasi, con sus anexos: Comuniadad, Tambo y Canchán (parie izọuierda).

Existen lâs siguientes autoridades políticas:

1. El Gobernador, nombrado por la Prefectura de Lima. Este tiene sus Tenientes-Gobernadores en:
Tupe
Puna de Tupe
Aiza
Colca
Catahuasi
Cachuy
Canchán.

Cada Teniente Fokernador tione a sil cargo, en cada uno de estos centros poblados, doce POLICIAS, organizados como un grupo de com- 
bate nillar. Estos son comuneros jóvenes que ayudan a "cumplir justicia". A estos Tenientes-Gobernadores los nombra el Subprefecto de la Provincia a propuesta del Gobernador. A los POLICiAs los nombra cada Teniente Gobernador. El Gobernador radica en Tupe.

2. El Alcalcie Municipal, es nombrado también por la Prefectura de Lima.

E1 Concejo Municipal de Tupe, está integrado por cuatro Regidores:

a) Regidor de Instrucsión, encargado de los Registros Civiles, que es e! primer Regidor y reemplaza al Alcalde en caso de ausencia o enfermedad.

b) Piej:dior de Dbras Públicas.

c. Sindico de Gastos.

di Siridico de Rentas.

Además el Concejo Municipa! liene su Secreiario.

En los anexos de Tupe existen Agentes Municipales.

Actuaimente se está gestionendo la creación de una Agencia Municipa! ミn la Puna da Tupe.

3.-El Juez de Paz, que es nombrado por la Corte Superior de Lima, anualmenie, cuando sa cierran los Tribunales da Justicia en el mes de enero. Para la eleccion del Juez se eleva una terna al Juzgado de Primera instancia de Yauyos, el clal propone a uno de ellos a la Corte. El Juez de Paz tiene dos accesitarios. Existen en Aiza, Catahuasi y Cacinivy. Jueses de Faz con sus respectivos acoesitarios. Estos son nombrados por el Juez de Prmeri Instancia de Yauycs a propuesta del Juez de Paz de Tupərge Puccinelli Converso»

4.-El Administrador Genera! de Aquas, es nombrado por el Ministerio de Fonento, por intermedio de la Dirección de Aruas e Irrigación. Anualmente para la fiesta de la limpia de la acequia, son nombrados por esta autoridad los Sub-Adminisiradores para cada acsquia, manantial o puquial, existen cerca de 15. Uno por cada toma. En Catahuasi hay dos Sui-Administradores; en Cachuy cuatro; en Chavín uno; y. en Chiure otro. 'Todos dependen del Administrador de Aguas de Tu$p=$.

Además do estas autoridades poíticas existen las autoridades comunciles que son elexidas cada primero de enero por la asamblea de los comune:os. Elios son:

1.-E! Personero de las Comunidades de Tupe, Catahuasi y Cachuy. Su cargo es concirmado por la Dirección de Asuntos Indígenas y dura dos años. 


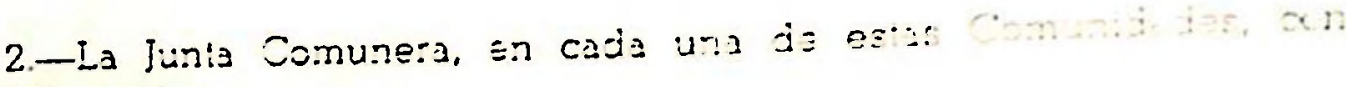
igua! durac:ón.

Está compuesta por el siguiente perso:za!:

a) Presidente

b) Vice-Preside:1te

c) Tescrero

d) Seczetario

e) Pro-Sezre!ario

f) Tres Vocaics

g) Fiscal

h) Pro-Tesorero

i) Dos Procuradiores.

El Personero es miembro integrante de esta Junia Comunera.

3.--El Presidente del Patronato Escolar, con Tesnee:o y Secteiato.

4.-Un Ecónomo encaryado de los Rejistios parrominiales co:l su Tesorero y Secrelario.

5.- El Bibliolecario Esco'ar.

6.--El Bibiiotecario Populat.

7.-- El Sacris:ún.

El Panteoreto, es nombrado por el Alcalde, anualmente.

Asimismo existen dos scciedades: la Sociedad Ganacieia y la Sc ciedad Agricola, cada unaldelellas con su fespectiva Junta Directiva. Estas son agrupacionés deeparticulares interpsados en el mejoraniento de la ganadoría y agricuitura.

III.-Hidrografía

Ríos.-En el área geogrífica del kauke en el Perú, existen tres quebradas estrechas, bien marcadas:

1.-La de Tupe.

2. - La de Chiure.

3.-La de Catahuasi.

La primera de ellas está atravesada por los ríos: Cuchapaya. Chancay y Tupe. Los dos primeros se juntan en el lugar llamado Apasa al pié del pueblo llamándose río Tupe hasta su confluencia con el río Cañele, en Catahiasi, a unos metros del puente sobre la carretera.

La segunda quebrada, Chiure, está formada por el río de su nombre que nace en Kimsoko (tres pantanos). En Canchán se junta con el río Cañete. 
Por la tercera, la de Catahuasi, pasa el río Cañete, que va engrosando sus aguas a nedida, que recibe eflunnies en todo su recoride, dos de ellos son el Chiure y e! Tuvə. Esta rivebrada es solamente una parte del valle alto de Cañete.

El río Chancay nace en los nevados situados al Norceste del piisblo de Tupe, llamados Kurivilka atravesando zonas de muchos minerales, penetra al pueblo por el lado noste. Sus aguas, muy batidas, son heladas y de sabor agruciable.

El río Cuchapava nace de cuatro lagos: Kakush-kotcha, Warmikotcha, Wacrakotcha y Cheikikotcha. silurdos en la Puna Este de Tupe; ingresa al pueblo por el lado noroeste, atravesando la úmica porción plana de la quebrada de regular extensićn, liamada la pampa de Cuchapaya. Sus aguas son menos fríts que his del Chancay y en ellas los pobiadores del pueblo en los meses de setiembre y octubre se bañan. También este río sirve para lavar ia ropa, diariamente vemos a hombres y mujeres ocupados en esta tarea.

Ei río Chiure nace en la puna Noreste de Tupe, en los nevados de Kapatoma (aqua :apada), lugar lla mado Kimsoko, al lado Oeste del nevado de Kurivilca. Después de cruzar la quebrada paraiela a Tupe por el Norte, echa su aguas al río Cañete o Yauyos, como se le llama en esta parte del valle, en el caserío de Canchán.

El río Tupe nace en las faldas del pueblo de su nombre y después de cruzar toda esta quebrada estrecha de Tupe, se junta en Catahuasi con el río Cañete. Este río sirve para la irrigación de toda la quebrada y de su cauce saleno innumerableselaceguias̄/des regadío para los diferentes andenes.

Los ríos de esta área geográfica son de curso irregular, cargados en écocas de lluvia y de poco caudal en tiempo seco. Su curso es ráp:do, atráviesan desfiladeras muy estrechos.

Laưos.-Existen en la jurisdicción del área cultural del kauke, los siguientes: Kakush-kotclia, Wakra-koicha, Want*r-kotcha, Chaki-kctcha y la mitad del lago Warmi-kotcha. La otra mitad pertenece a otra ju-isdicción. Todos ellos situados en la Puna Este del área y formados por los deshie.os de la Cordil'era Occidental. El lago Warmi-kotcha que tiene la forma de una mujer, tiene sus aguas represadas que irrigan el valle de Chincha. Idemás el pueblo usa ias aquass de los lásos de Chay-llwa y Chullumpe que están represadas por los tupinos y cliyas aguas van al río Cuchapaya. Estas pertenecen a Pampas. 


\section{CROGRAFIF.}

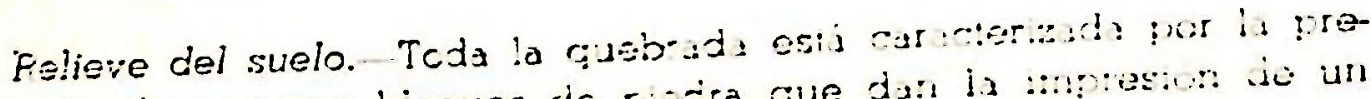

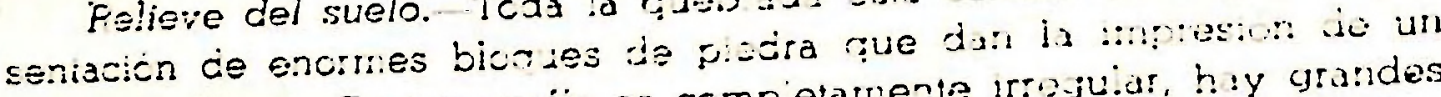
gran calacismo. Su topojraila es comp.etamente troju.ar, hay cynandes cerros, excrmes peñascos. grandes nevados que som parte de la Cor-

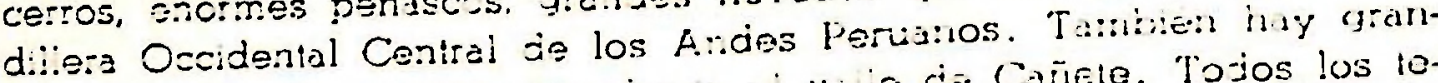

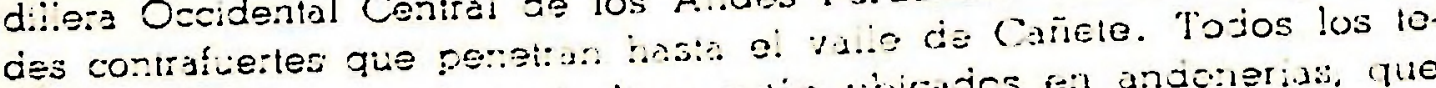

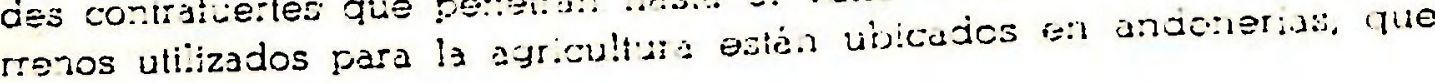
cubren el ialud.

Pecursos mineroles. Exiz dira es bsstanie rica en pirtas. y se coouentrs en dilerentes iugares, eupesicimenie en el camino de lu puna. jata, rercurio, coibre, mirrro', sal gema, que no son explolados. Su rioueza en mártaol es grande, los hay de diteientes c'ases y colores: morado, rojo y blanco. Sis recursos minerales están sin explotación. pero los lupinos tienen la impresión de que su zona es bastante jica

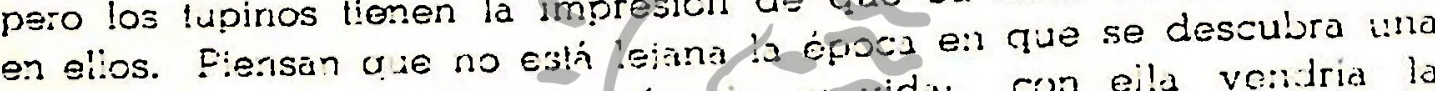
b:iend veta y cambie la silia-ion se sul vida con eila voudria la carretera, el progreso, dicen. En las calles dí pueblo, on el fondo de les rios y en ceneral doride lleja e! equa, en toda la quebrada, el susio brilla, como si hujiera oro er polvo, son particulas de mica o pirita que tienen un color amaril!o y que dan la in:presión al viajero de su grai r:gueza mineralBlolloteca de Letlas

\section{ZONAS LENTRO LEL A.PEI.-}

Perfeciamente bien marcadas se distinguen en esta área geográfica tres zonas:

1. La Puna, que es la zona frígida, a!ta.

2. Las Quebradas, cejes de sierra, zonas frís y gue consi:tuyen la parie media: Keshwa.

3. El Valie, zona cí.da y baja, liamada "yunga".

Cada una de estas zonas, geográlica y culturalmente, tiene su propia caracierística que la distingue cie las otras. De ahi que en nuestro estudio etnológico las hemos considerado aparte.

Mientras que en Catahuasi, s:tuada en la parte baja, abunda el limón, la palta, guayakas y mangos; el algndón y yuca; en Tupe y Cachuy. que están en la parte media, los duraznos, lunas y mitos son las frutas de mayor producción, además de la papa, cebada y trigo. Én carmbio, en la Puna, parte a!ta, sólo existen pasiss naturales. 
La parte baja está entre los 1.200 a 1.500 meiros. La parte media, s:er:a propiamente dicia, entre los 1,500 y 3,200 metros; y la puna, entre 3.200 y 4,200 meiros sobre el nivel del mar.

En la parte alta la riqueza de auquénidos es considerable, debido a que, para estos animales, constituye una zona propicia, porque está l:bre de las asechanzas de los cazadores. En la parte mejia y baja los vacunos, cvinos, cabríos, caballares y caprinos son el ganado que más abuncia.

VI. CIIN:A.-

Fe acuerdo con lás zonas señaladas dentro de esta área geográfica, el clina presenia características peculiares para cada una de elias. En la puna es frígido illegando a temperaturas bajo cero, durante los meses de junio a agosto que son los de las "heladas". Mientras que en nov:embre a marzo, época de lluvias, de nevadas y granizos, la temperatura es menos riguresa.

En la parie media, Tupe y Cachuy la temperatura es fría generalmente toto el año. Siendo los meses más fríos de junio a agosto. De setiembre a noviembre es más templada. De diciembre a marzo es la época de lluvias, que son muy abundantes y copiosas. Durante esta época sàle el sol y expuesto uno a sus rayos hace calor, pero en la son.bra mucho frío. Las madrugadas más frías. Esto se observa todo el año, generalmente. Cachuy por estar unos 400 metros más alto que Tupe, es de clima más trío. Hemos hecho diferentes observaciones en nuestros viajes en "elp pgeblouldeitupel Sobre/tas Qariaciones del clima, de lo cual deducimos que es bastante parejo, las precipitaciones son rorma ies para esta zona.

En la parłe baja, Catahuési, Canchán y Chavín, el clima es regular- . mente cálido todo el año. Siendo la época de lluvias de diciembre a marza.

Fenćmenos atmosféricos y cósmicos.-La quebrada de Tupe es azotada anua!mente por fuertes vientos, especialmente durante los meses de lluvia. En el mes de enero éstos se acentúan más; y también los həy, esporádicamente, en julio o agosto. Pero el más temido es el de enero porque destruye las sementeras.

Durante los meses de lluvia toda la quebrada se cubre de una neblina muy densa Tákui-tákui, apenas puede uno distingliir a uno o dos metros a su alredecior.

En esa época el pueblo está expuesio a las "aiuancadas" (huaicos) o sea la presencia de fuertes deslaves. Hace muchos años por el río 
Chancay uno muy viciento se lievó el puente de onitid a .. ... isd, Willakanka, que era muy antiguo y de piedra.

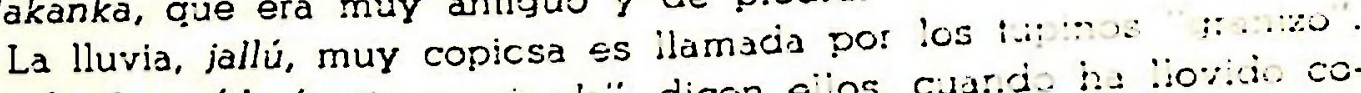
"Anoche ha caído fuerte granizadu", dicen ellos, ciardo ha :io id copiosamente, fuera de lo normal. Llamen "rite" cuarido cae .a ...... como confites blencos.

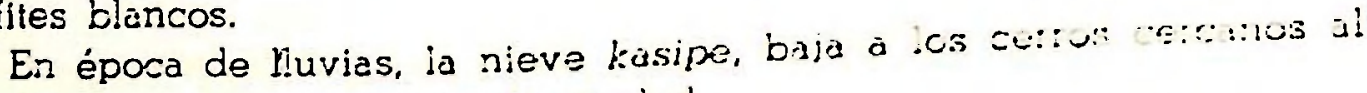
pueblo, pero nunca nieva en la ciudad.

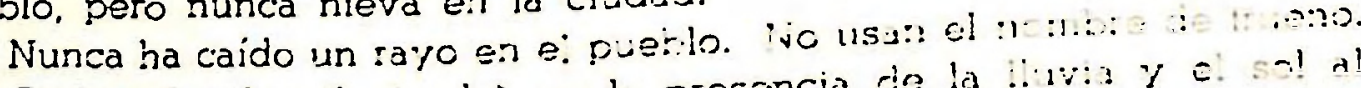

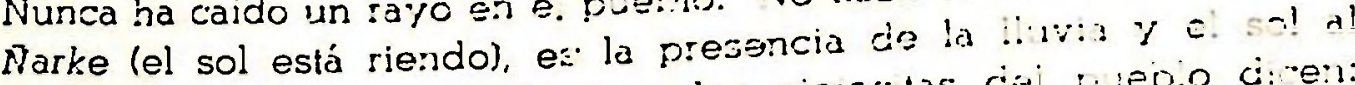
mismo liempo. Cuondo sucede és!o, las viejextas dul peoin ciren: Narke jallkiwa Inte nup kusho" (el Sol estri riendo, diumirindo Ilueve).

Lespués de la lluvia y cuando sucede el iurtee, sale el arco iric. turumanlla. Dicen que sale éste de lcs puquiales y no sa dele tomar el agua de ellos porque uno puede morir.

Los meses de sequía son las de abril a novientíe. Este año ella ha afectado al pueblo durante los meses de lluvias. Lus l'ülas han sido escasas lo cual ha perjudicado las cosechas.

A. Sol, lo llaman Inle, como en keshwa. Durante los meses de verano llega a la plaza entre las 8 y 30 y $9 \mathrm{a} . \mathrm{m}$. y desaparece de ella a las 4 p.m. En época de lluvias el Sol ileza a la plaza entre las 7 y 30 y $8 \mathrm{a} . \mathrm{m}$. y desaparece a las $5.30 \circ 6 \mathrm{p} . \mathrm{m}$. El cielo aparece completamente despejado de mayo acoctubre. Anuálmente, para el dia de Sanía Rosa (30 de agosto) uno 8 dos días anles siempre llueve.

La luna, Pashe. Sus cuatro fases son:

Luna nueva: killa (como en keshwa).

Cuàrto cresiente: sin denominación en kāuke.

Luna llena: pura llena (también en keshwa).

Cuarto menguante: "está bajando para luna vieja" Jiriail-kíwa.

Cuando nace la luna dicen: Pashe mansa, madre luna, nuestra madre. El día de luna nueva es kilia. Pashe jiwaski, son los días en qua no hay luna. La luna está muería.

Al eclipse le llaman: Eklipsh-haw'e. El eclipse de luna es pashe eklipsh-hawe.

Wajara es el nombre de las estrellas. Cada grupo o constelación tiene su nombre: chaj-ra a la escalera; ushukia, la perdiz; mayo, el río; capritillas, las "siete cabrillas". Cuando aparecen claramente es señal de mucho frío. 
Los temblores son anuncio de epidemia, de retiro de lluvia o deiniciación abundante de ella. Así también pueden ser presagio de una guerra. Esta zona es poco afectada por los temblores.

VII. FLORA.-

Características generales de la flora.-Perfectamente diferenciados existen tres tipos de vegetación: la yunga con toda la variedad de plantas cultivadas propias de una zona cálida, (más abajo enumero cuales son las que caracterizan principalmente esta área) la keshwa que se extiende desde los 2.000 metros a 3.200 metros en las quebradas estrechas cultivándose la papa en toda ella, el maíz hasta los 2.900 metros sobre el nivel del mar; y la de la zona frígida (puna) donde no se cultiva nada, su flora es pluviofica, abundando los pastos naturales, el ichu y un sinnúmero de plantas pequeñas de uso medicinal. En el límite de la zona yunga y keshwa existe una gran extensión desértica, de flora serofítica, donde abundan varias especies de cactus. En la zona keshwa con el riego y la lluvia se desarrolla uná fuerte vegetación de plantas pequeñas que tienen usos medicinales, siendo dos o tres las especies que recolectan para alimento. Todas eslas especies silvestres son conocidas por los moradores y muchas de ellas no hemos podido identificarlas todavía, estamos recogiendo sus nombres en kauke, comparándolas con sus nombres en keshwa y recolectándolas para formar un herbario a fin de que pueda servirlá algún especialista que quiera realizar un esludio en esta zona.

1.- Plantas cultivadus:

De origen amerivano

De origen extramericano

a) Alimenticias:

CEREALES: maíz (Zez iMays)

quinoa (Chenopodium quinoa)

LEGUMBRES: frejol (Phaseolus vulgaris)

pallar (Phasseolus Lunatus)

PLANTAS TUBEROSAS:

achira (Canna edulis)

olluco (Uilucus tuberosus)

trigo (tritivum sativum)

cebada (Hordeum sativum)

haba (Vicia Faba)

arveja (Pisum sativum)

lenteja (hens esculenta)

oca (Oxalis tuberosa)

mashvra (Tropacolum tuberosum)

ninguna 
yuca (Manihot utilissima)

camote (Ipomoea batatas) (Yunga)

papa (Solanum tuberosum)

yacón (Polymnia sonchifolia)

\section{FRUTALES:}

pacae (Inga Feuillei) (Yunga) granada (Punica) (Yunga)

chirimoya (Anona Cherimolia) (Yunga) caña dulce (Saccharum offi-

cinarum) (Yunga)

palto (Persea Americana) (Yunga) limón (Citrus) (Yunga)

guinda (Prunus capollin)

cerezo (Malphigia) (Yunga)

higo (Ficus carica)

durazno, melocotón, abridor

(Prunus)

granadilla (Pasiflora ligularis)

naranja (Ciirus) (Ýunga)

guayabo (Psiduim guayava) (Yunga) pláiano (iviusa Farca'isiaca)

(Yunga)

lúcumo (Lucuma obovata) (Yunga)

sandía (Citruilus vulgaris)

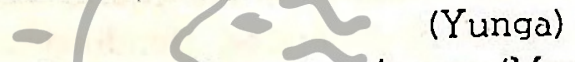

pepino (Solanum muricatum) (Yunga) níspero (Ḿespilus germanica)

(Yunga)

manzana (Pirus Malus) (Yunga)

manço (Mangifera indica)

Biblioteca de Letrunga) "Jorge Puccinelli Conve(Yunga)

lima (Citrus) (Yunga)

uva (Vitis Vinifera) (Yunga)

câfé (Coffea arabica) (Yunga)

CUCURBITACEAS Y HORTALIZAS:

zapallo (Cucurbita)

ajcs (Allium sativum)

tomate (Solanum lycopersicum)

beterraga (Beta vulgaris)

calabaza (Cucurbita moschata)

cebolla (Allium cepa)

col (Brassica oleracea)

coliflor (Brassica c'eracea)

lezhuga (Lactuca sativa)

rabo (Cruciferas)

rabanito (Raphanus sativus)

zanahora (Daucus carota)

yerba buena (L.abiadas) 
CONDIMENTOS:

aií (Capsicum)

rocoto (Capsicum)

huacatai (Tageles minuta)

b) Planta Textil:

algodćn (Gossypium peruvianum) (Yunga)

c) Planta forrajera.

d) Arboles y arbustos: sauce (Salix Humboltiana)

alfalfa (Medicago sativa) nogal (Juglans neotropical) eucalipto (Eucalyptus globulus) aliso (Ainus !oruliensis)

el Fiores:

czucena (Lilíaceas) margarita (Compuestas) pensamiento (Vio'áceas) rosa (Cruciferas) (Yunga) gladiola (Irideas) clavel, clavelina (Cariofileas Lochnera) crisantemo (Campuestas) dalias (Compuestas) blloteca de Letras romero (Labiadas)Jorge Puccinelli Converso" manzanilla (Compuestas)

cala (Irideas)

f) Medicinales: manzanilla (Chrysanthemum Parteneum) yerba buena (Labiadas) yerba luisa (Cymbopogom cilratus) hinojo (Umbelíferas) nogal (Juglands Neotropica)

2.-Plantas Silvestres.-(Utilizadas por el hombre)

a) Frutales:

mito (Carica Candicans) (O.A.) (')

tuna (Opuntia ficus indica) (O.A.)

tumbo (Passiflora mollissima) (O.A.)

mancha-mancha (Oxalis Corallecides) (O.A.)

(1) O. A.: Origen Americano. 
umpulio

acuma

pitixaia o an-hairo

No identificadias

sikuruma

(Puna y Zona Ana Kestima)

sayara

purpuro

b) Flores:

huamanripa (Saxifraga magellanica var. peruviana) (O.A.)

retama (Spartium junceum) (O.E. A.) (")

arredilla

kole

capra

cinca-uaita

putchuaita

c) Textiles:

maguey (Agave americano) (O. A, México)

d) Arboles y arbustos:

quinuar (Polylepis racemosa) (O.A.)

quisuar (Buddleia Incana) (O.A.)

alamo (Buddleia Iongifolia) ( $Q A_{A}$ )

sauco (Sambucus peruviana) (O. A.)

guarango (Accacía macracantha) fo. A.pnverso"

molle (Schinus molle) (O.A.)

tara (Caessalpinia tinctoria) (O. A.)

retama (Spartiurn junceum) (O.E.A.)

siaraka

iuch-iuch-she

traza

sayara

bate

murmuro

chachullo

pase

mallai

uajar-uajra

trek'trek'ta

sauble

No identificadas

(Zona Keshwa y Funa)

(f) O.E.A.: Origen Extra-Ämericano. 
e) Medicinales:

1. wa!lua o kúlen

2. Sumatia $\circ$ menta

4. lianten

5. trarka u ortiģa
a) xajirarisa
b) arkire ortiga
c) wantrarka
d) mula-ryanusho
e) chilentrarka

6. berro

7. congona

8. poke

9. huamanripa

10. sabela (sábila)

11. ruda

12. cola de caballo

13. pàico

14. pillo o amor seco

15. perro lengua o lengua de perro

16. papancho o yerba mora

17. verbena

18. matica

19. konto

20. k'ole

21. verdolaga

22. pusanko

23. ankoripa

24. escorsonera

25. amañakaya

26. wamanchilka.

27. ñununta

28. chechahuarco

29. romero

30. keske

31. matagusano

32. marco o artemisa

33. trekese

34. valeriana

35. kalauala o pukasike 
3E. suelda con suelda

37. Chilke

z8. kuy-puco.

VIII. FAUUIA.-

Carocterísticás generales de la faund. La fanna de esid tros es mu rica en insecios y aves. Ademús es importanie zu tignezs en manileros. Se calcula que en ganado ovino hay cerca de 20,000 cabezas. La puna de Tupe es considerada como una de las zonas més ricas en anquandos dentro dei departamento de Lima.

De las espezies silvestres no utilizan especia!nento, ninguna, salvo pequer̃os inserios que les siren para ternedios. No practican la caza.

En capitilo respectivo: genade:ia, enumero las enpesies domesicadas y sus usos. El estudio de lus espezies silvestres queda reservado para lin trabajo especiál.

IX.-TUPE.-

"Es el pueblo más histórico y origina: de la provincial. Su topografía sembracia de peñones trae visiones de cataclismos". Sus mujeres y sus "huahuas" con los pañuelos en la cabeza. Sus mujeres con su gran fuerza y destreza para llevar cargas pendientes de la frente le dan el hilo de un ininerario lejano teepe. he venido de lejos, cargando y abriéndose camino en la historia. Y su lengua no la ha olvidado. El incisivo "kauke" es su idioma oficial, de raza yr procedencia. Pueblo de prófugos del Tiawanaku, cuando la destrucción geológica o el arrasamiento de la invasion?. Pueblo de mitimaes metido cerca de los "yauyos" temibles para que se exterminaran entre sí en caso de desahogo beligerante?. ¿Avanzada aimaré enraizada cerca del inexpugnable Tupinachaka que se vino en busca de libertad para vivir su rebeldía?

Quién sahe que ensamble gitanero existe en la historia de este pueblo seguramente estropeado. Le queda un dejo de amargura $Y$ un "escape" de aburrimiento anguloso. Interesante su vida de colores sociológicos vivos. Es chacarero y ganadero. Canta y loca y baila singularmente. Es primitivo en sus manifestaciones. Por eso es sincero. Y cliando quiere, quiere". (De "YA.CHAYHUASI". Organo de los maestros de Yauyos. Año Il. Yauyos. Lima, Perú. Setiembre y Octubre de 1941. No 10, pág. 4).

Este cuadro de un maestro yauyino, sintetiza el espíritu de lo que es el pueblo de Tupe. Gentes sencillas que en número reducido con- 
sevan for la luerza de sus costumbras, de sus tradiciones, mucho de lo oue iue el Antiguo Perú. Es un núcloo apenas hoy de unas 1,000 srsonas.

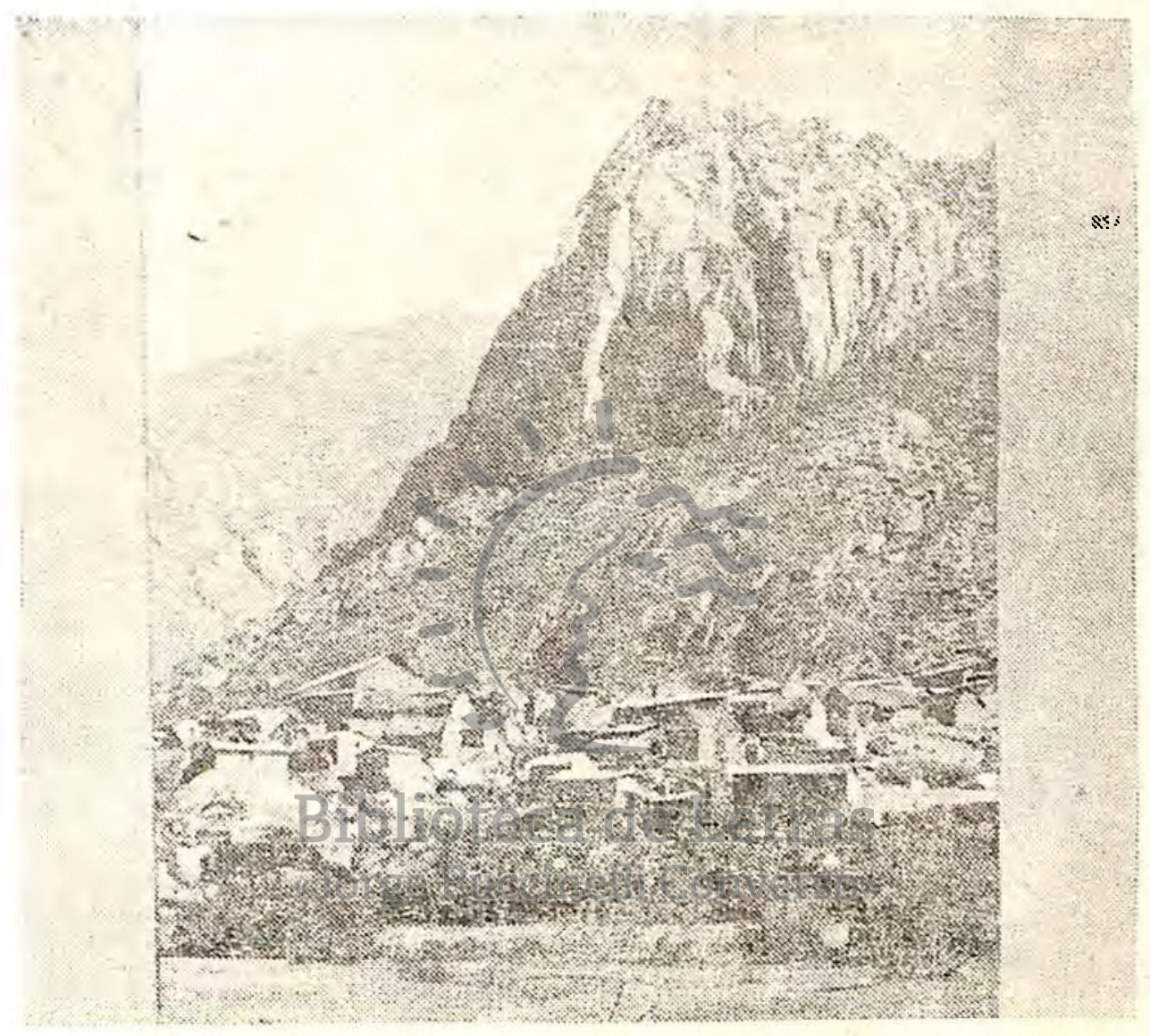

Vista de Tupe. Al fondo, Tupinachaka

El pueblo se halla situado entre dos cerros majestuosos, por el lado Nor-oeste el TUPINACHAKA (Tupe Viejo) y por el lado Noreste el PUPRE. El primero es su cerro tutelar, en él están simbolizados el vigor, la pujanza, el impulso de lo que es el espíritu de los tupinos. "Somos rebeldes y erguidos como ese cerro", dicen "cs moradores de este pueblo. A través de las generaciones que se han sucedido, lo han considerado como su dios tutelar. En sus faldas encontramos hoy los restos de viviendas, adoratorios y cementerios de la ciudad pre-incaica. La ciudad de los antiguos pobladores de esta quebrada. De estas ruinas arqueológicas emerge la parte alta del Tupinachaka con su for- 
ma tronco cónica de rocas lisas, coriadas a pico y en dondi oxieton pictografías que se conservan claramente. Lus caras laterrles do este co no truncado son tan lisas que en las noches ce luns. refiejan la luz corno si fueran espejos.

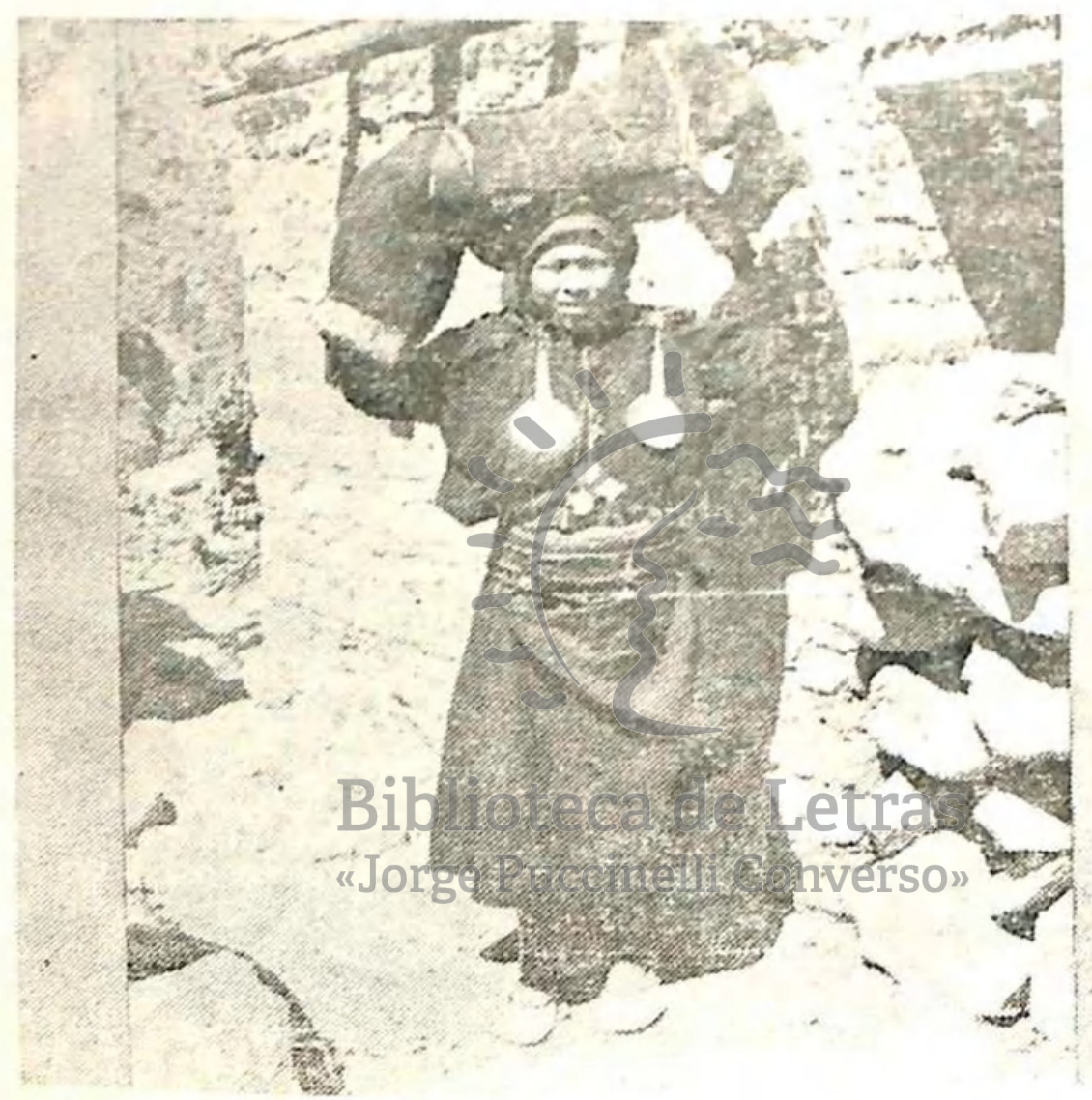

Mujer con traje típico cargando a su hijo en la "tira" (cuna)

Las ruinas están situadas a unos 20 minutos del pueblo. Los tupincs dicen de ellas: "son los restos de los "gentiles" nuestros abuelos"; y por eso les tienen gran veneración. Las miran y hablan de elias con respeio y temor. Nunca se atreven a tocarlas. Solamente los alumnos del Colersio de ve\% en cuando vän con sus maestros en excursión, a conocerlas.

Antiguamente en la súspide del cerro dicen que había una gran crixz de plata. Para el prinero de enero de cada añor la Junta del Pueblo que estaba formida por el Alcaide, que era el Jefe (ol VARAYOC) 
con su vara cis plata, el CAMACHICOC y el REGIDOR, reunían a to. da la Comunidad y en medio de gran regocijo, música y cantos, para los cuales tcios estaban convenientemente vestidos y adornados; designahán una comis:ćn que era la encargada de llevar flores a la cruz. El CAMIACHICOC, que tenía la función de vigilar a todas personas de la comuniciad, averiguando de casa en casa lo que hacían y además el cuidador de las siembras; era el que dirigía esta ceremonia. Y ella lenía por objeto pedir que el año que ss iniciaba fuerz bueno. Actualmenle las personas de 35 a 40 años nos informan que han visto de niños la cruz y la reunión del primero de enero. El cambio o sea el cese de la cerenonia debe haber sido hace unos 25 a 28 años debido sobre todo a la extinción de la Junta del Pueblo y su reemplazo por la Agencia Municipal, desapareciendo el VARAYOC, el CAMACHICOC y el REGIDOR. Hoy existen tres peanas de piedra en la cúspide del Tupinachaka.

En el pueblo todos conservan el recuerdo de la existencia de 6 ayllus o parcialidades. Actualmenie cada dueño de casa sabe por sus escrituras a qué barrio pertenece; todavía anualmente, para la fiesta del Corpus Christi, funcionan dos de ellos que están debidamente organizados, como las sociedades religiosas. Estos ayllus son:

1. Nutko

2. KollanaBiblioteca de Letras

3. Xilasullka

4. Yañac

5. Aiza

6. Pursullka

El ayllo o parcialidad de NUT'KO está situado en la parte alta del pueblo, junto al cementerio, y su jurisdicción llega hasta el Callejón de San Pedro cerca a la Plaza. Ocupa el lado Noroeste del pueblo.

KULLANA o KOLLANA, también en la parte alta, ocupa el lado Noreste del pueblo, al lado del Cerro Pupre. La calle Unión que va de la plaza al Cementerio es el límite de este ayllo con el anterior.

La parcialidad de XILASULLKA ocupa toda la parte inferior del pueblo, lado sur.

YANAC, ayllo que funciona actualmente en casa de Patrocinio Casas, ocupa la parte central del pueblo y va desde la Iglesia hasta MILLPO. 


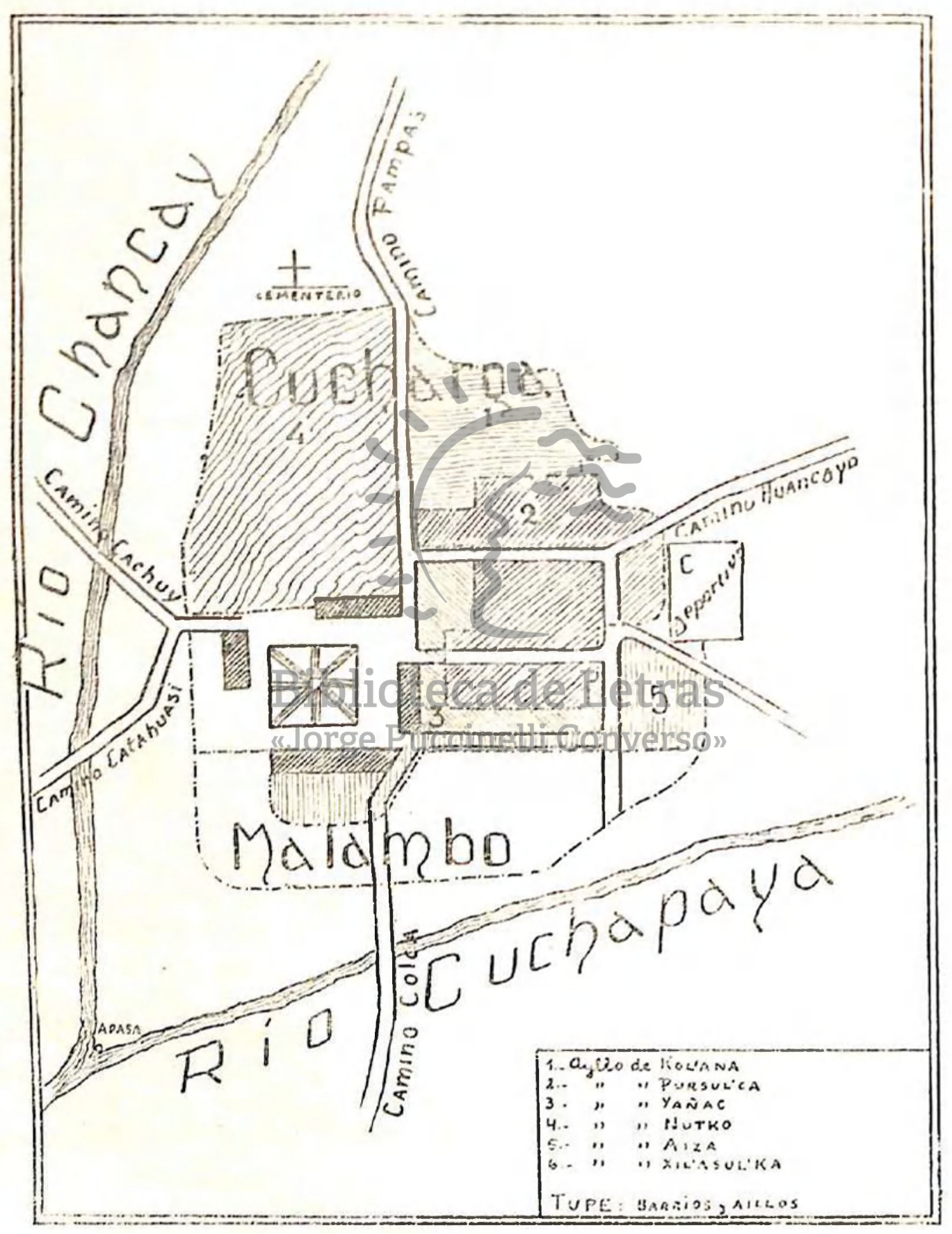


AIZA, situado debajo del ayllo de Kollana, ocupa el lado Este central del pueblo. Su área es irregular y como un callejón llega cruzando parte del centro del pueblo a la parte inferior Oeste. Tiene sus estatutos pero no funciona.

La parcialidad o ayllo de PURSULLKA, está ubicado en el centro del pueblo. Y dentro de él especialmente en un cuadrilátero llamado PAMPAIPOZO. Funciona hasta la fecha para el día de "Nuestro Amo". Tiene sus estalutos.

El documento encontrado en el Archivo Arzobispal, referente a un juicio de hechicerías del año 1661 en este pueblo, se menciona el ayllu de Pursullka como residencia de la acusada. Así también el de Nul'ko y Aiza.

Estos seis ayllus están divididos en dos barrios:

1. Cucharga

2. Malambo

El primero corresponde a la parte alla del pueblo y el segundo a la parle baja. (Janan y Urin Saya).

Hoy día los habitantesusan esta división: cucharguina y malambina. No hemos podido conocer desde cuando existe esta denominación de barrios, solamente parece, por algunas referencias y no mención en documentos antiguos, 'que su denominación es posterior a la ayllal. Hay coincidencia en esta división de 2 barrios con la de Lima: Barrio alto, Cocharcas; y Earrio" bajo, Malambo. Comparando's estos dos barrios indudablemente que Cucharga por estar en la parte superior y tener topografía menos irregular, tiene alguna preponderancia en el pueblo. Nunca las procesiones van por la parte baja, Malambo. Cuando se realizan los bailes de la Herranza y la Pascua, tampoco recorren la parte baja, los visitantes, ni se alojan alli; no existe ningún trazado de calles, la mayoría de las casas están en la parte superior. Hay otro sector, intermedio entre estos dos barrios, la Plaza principal y única del pueblo, ellos la lläman "la cuadra", es una parte completamente plana, lugar de reuniones, fiestas, etc., esto hace de elía la parte más importante y principal. Así es que en realidad ninguno de los barrios tiene la importancia que la parte céntrica del pueblo, "la cuadra". A su lado están Pursullka y Yañac, ayllos que realizan sus acuerdos y fiesta actualmente.

El pueblo ocupa un terreno cuya lopografía es irregular. Tiene un ángulo de inclinación entre las primeras casas de la parte superior a 
las Litimas junto al río Clichapaya en la par:e baia j. anc. $201 \mathrm{~m}$

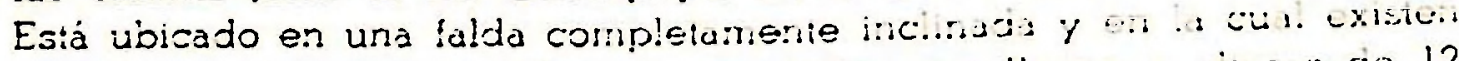
desparramados enormes blogues je piedra que llecjul a di:is de 12 a $15 \mathrm{~m}$. je alto por 8 a 10 de ancho.

A.! pueblo llegan los siguientes cummos:

1. Por el Oeste: de la costa. Catihuasi-fizratides.

2. Por el Este: de Huancayo, es el camino de la puna.

3. Per e! Sur-oeste: de Cacra. Cruzis Warlute y Colca.

4. Por el Noroeste: de Paripas, antiquá capital cie! distrio. Pasa por el nevado de Kurivilca.

5. Por el Norosite: de Cachuy. Pasancio por Chiure y Anchike.

Cuando se llega por el camino de da cosla a! pueblo, se tiene que cruzar el rio Shancay, por el piente de WILLAKANKA. Y después de dos zig-zage muy empinados se encuentra uno en la Plaza o "cuadra" que ocupa exactamente la parte centrica de la ciudad de forma trapezoidal. Al lado derecho tiene la Iglesía giue mira hacia el Oeste. Al lado izauierdo la casa de dos piscs de la Sociedad Religiosa do Corpus Christi, llamada el "Calfón" de Nuestro Anro, que es una de los mejores del pueblo. A su lado un pasaje y iuego la cárcel. Al este, el nuevo local de dos pisos para el Centro Escolar de Varones. Edificio que está siendo construído por la Comunidad. Al ccslado oesie de la plaza se encueniran ubicadóslos actuales lócales de lás Escuéas de Mujeres y Varones.

El pueblo estri atravesado por ma calie principal que va de la Plaza hasta la parte alla, Cucharga, y llega a! cementerio. En el centro de la calle corre una acequia cuyas aquas vienen del río Chancay. Esta clase de acequias en el centro de la calle aparecen en todos nuestros pueblos serranos. También esta calle corresponde al antiguo camino a Pampas, que era la capital del disirito, del cual Tupe era uno de sus anexos antes de 1936. Diariamente para la inscripción en los registros civiles, elecciones, etc., tenían que viajar; es la ruta más antiçua del pueblo, se sabe que por ahí bajó Santo Toribio de Mogrovejo; Arzobispo de Lima en el siglo XVI, en su visita, pastoral a la Provincia. Cosme Bueno y Raimondi nos cuentan de los 5,000 escalones que había que bajar desde Pampas a la Plaza de Tupe.

En el centro del pueblo y al lado este de la plaza se encuentram otras 3 calles de una cuadra cada una, bien reclas que forman el cuadrilátero de construcciones correspondientes a la Parcialidad de Pursullka y Yañac, por ellas tradicionalmente pasan las procesiones del 
pueblo. El resio está formado por bloques de casas o casas aisladas, formando las diversas zonas.

Todas las casas tienen como material de construcción la piedra y si tienen segundo piso, este es de adubes. Todos los techos son de dos aguas: con ichu o con calamina.

Las mejores coristrucciones del pueblo corresponden a los "calfones" o sea los locales de las Sociedajes o Instituciones religiosas, que han sido construídas por los socios de ellas y que solamente les sirven para su celebración anual.

La Plaza constituye el lugar de reunión de los comuneros dominicalmente para tratar diversos asuntos de la Comunidad; asimismo constituve el centro de actividades en los dias de fiesta. La campana de la iglesia, cumple dentro del pueblo una misión importante, mediante toques especiales que todos corrocen, llama a misa, a la escuela, a fagina o sea trabajo comunal, a reunión de la Comunidad, a reunión de autoridades del pueblo, a fiestas, para anunciar la muerte de un adulto (doble), de un párvulo (repique). etc. La campana es tocada por el sacristán o el ecónomo, no hay recuerdo de la existencia de una persona especial como campanero. Constituye la plaza el patio de recreo de los alumnos de la Escuela. Asimismo, en las tardes, fuera de las horas de clase, se reunen los muchachos del lugar a jugar foot-ball y los días domingos, hombres y mujeres a veces para jugar volley-ball.

Frente a la puerta principarde la folesia, haysun terraplén, que es llamado el "malecóför donde diariamente desnués de sus labores cotidianas, los hombres se reunen a conversar, contemplando desde ahí todo el camino al pueblo desde Catahuasi y en el fondo antes del crepúsculo ver el mar, especialmente durante los meses de junio a noviembre, durante los cuales la visibilidad es perfecta.

Diariamente a partir de las $5.30 \mathrm{a}$. $\mathrm{m}$. el pueblo está dedicado a preparar sus actividades diarias. Los del barrio alto acuden a recoger agua al río Chancay y los de Malambo al río Cuchapaya. Hacen sus compras, preparan sus alimentos, arreglan sus fiambres y comienzan a salir por los diferentes caminos del pueblo a sus chacras llevando a pastear sus ganados, con sus TAKLLAS, etc. Solamente cuando el sol llega el pueblo buscan a sus vacas y comienzan a ordeñarlas (a "lecharlas") antes no lo hacen.

Tupe constituye la médula del área cultural del kauke en el Perú, en él, reside ahora la tradición de sus antiguos pobladores; ha resistido, por sus condiciones especiales, las fuertes presiones exteriores, primeramente la dominación incaica y luego la conquista española. 


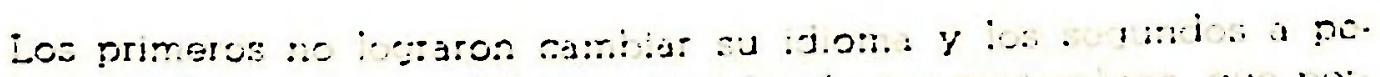

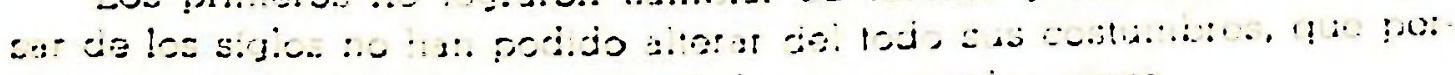

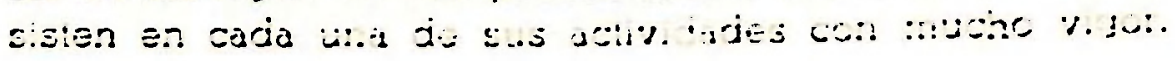

\section{X.-LA POBLFCICN Y LA LENGUA.}

La poblacicin.

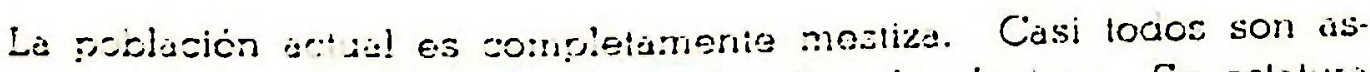

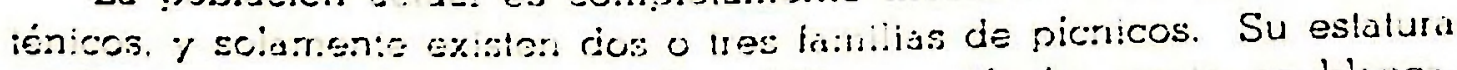

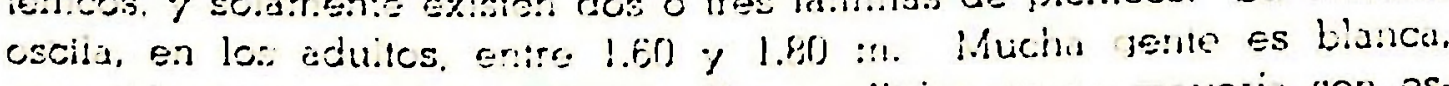

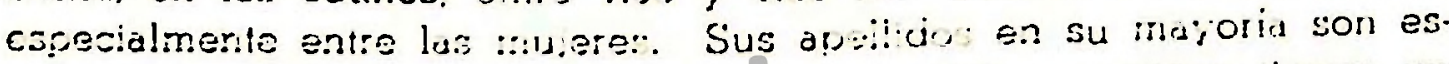
pañoles. Tienen gran sensibildad artistir. c.dultos $y$ ninos lienen un "oido" refinato esonocen y eitchan gralguier lone de núsico o un tono rulievo, lo aprenden ficilniente ron scio oirlo dos o tres veces. Son bustante hábiles para las mutermalcas. debido a que constintemente tienen que trabajar con números. Fil sor socio de muchas sociedades religiosas, ganaderas, agricolas o deportives, donde prostan y reciben dinero, paran in!ereses a crada una de est i.; sceiedades $y$ a la comunidad, motiva que ellos sean rápidos en sus oreraciones de suma y resta y lanto por cienta. Una mujer prontamente puede indicar un tanto por ciento determinado. Osubuer huma escotrade sus características; siempre que se esté «Đpresenciaidelin GJupo de tupinos o tupinas los veremos conversando animádamente, liéndose, bromeando.

En sus viajes son despiertos y no se quedan callados ante nadie, no son noda huraños. Tienen gran prepcupasićn por quedar bien en sus "cargos", pasar en medio de derroche y ceremonial sus fiestas, cuidando el prestigio de la familia en quedar mejor que los otros; hacer que su "cargo" sea recordado muchos años como el mejor, para sllo no escatiman esfuerzos, sacrificios, ni dinero.

El hecho de que lodos sean propietarios, que no dependan en su irabajo de nadie y que su esfuerzo sea su único cápital productivo, ha desarrollado altamente su espíritu independiente.

La población ha sufrido muy pocas modificaciones en el transcurso del liempo. Tenemos los siguientes datos de ella: 


\begin{tabular}{lccc}
\hline N. & Año del Censo & Distrito & Tupe \\
1. & 1940 & 1,366 & 524 \\
2. & 1938 & - & 589 \\
3. & 1926 & - & 916 \\
4. & 1876 & - & 687 \\
5. & 1836 & - & 599 \\
6. & 1790 & - & 419 \\
7. & 1602 & & 385 (sic)
\end{tabular}

El Censo de 1940 indica la población de los centros poblados de Tupe en la siguiente lorma:

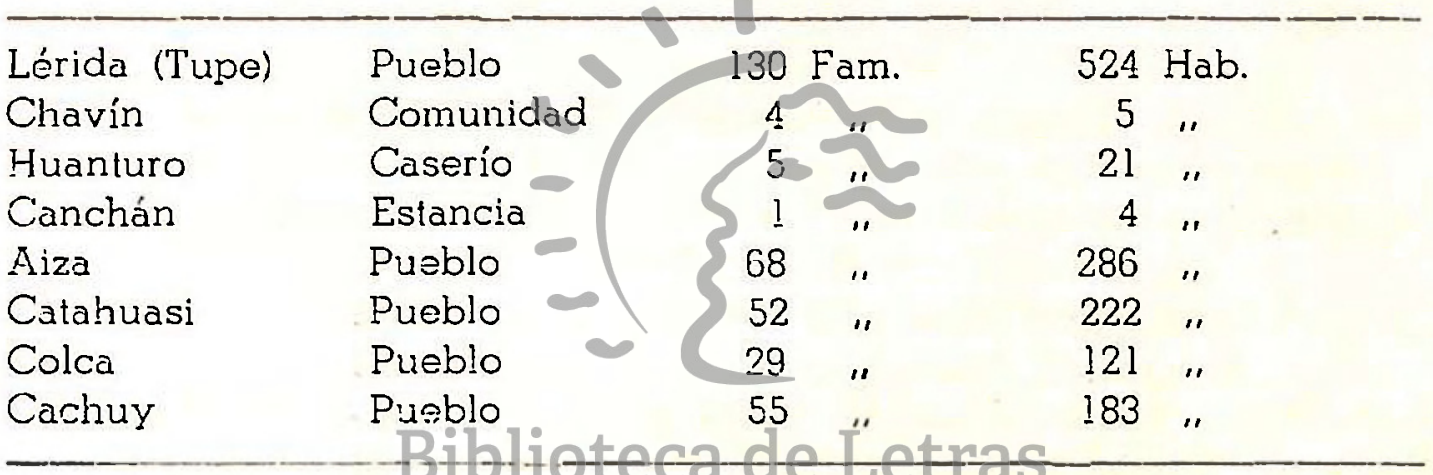

El Censo de 1938 está en läPirección de Asuntos Indígenas en el expediente de reconocimiento de la Comunidad, fué hecho el 20 de setiembre de 1938, y dice:

Hombres mayores de edad: 117 Hombres menores de edad: 142 Mujeres mayores de edad: 187 Mujeres menores de edad: 143

El Censo de 1926 está en el libro de Registros Matrimoniales de Tupe correspondiente a ese año, y dice que hay 195 jefes de familia en el pueblo y 916 personas, aquí están comprendidos los habitantes de Aiza, Colca y Huanturo, además hay muchas duplicaciones.

El Censo de 1876, corresponde el Censo General de Habitantes del Perú levantado ese ario. Aparece este dato en el libro publicado por 
Manuel Atanasio Fuentes. Lima. Imp. del Estado, 1876, pág. 286. Da los siguientes datos:

$$
\begin{array}{ll}
\text { Hombres: } & 354 \\
\text { Mujeres: } & 333 \\
\text { Total: } & 687
\end{array}
$$

El dato de población de 1836 se encuentra en un documento del Archivo Histórico del Ministerio de Hacienda y Comercio, № 0206, en una "Matrícula de Indígonas de las Prcvincias de Yauyos con sus nueve distritos por el subprefeclo coronel del ejército y comandante militar don Juan Evangelista Vivas y apoderado fiscal don Pedro Bandini en $1836 "$.

Indica Originarios y Forasteros con tierras en el pueblo de San Bartolomé de Tupe

Duna de Tupe

Hombres: 243

Muieres: $\quad 356$

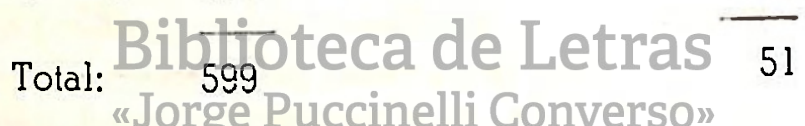

En otro documento encontrado en es!e Archivo Histórico, el N! 0118 del año 1830 que es un "Padión de Indígenas Contribuyentes de la Provincia de Yauyos". Indica:

\section{Contribuyentes}

8 entrantes (menores de edad)

3 contribuyentes para la puna de Tupe.

El dato de población de 1790 consta en el Archivo Arzobispal de Lima, en un documento que indica el $\mathrm{N}^{\mathrm{o}}$ de habs. de la Dociniria de Pampas de Yauyos. Para Tupe señala 419 personas.

El Censo de 1602, se refiere a la visita Parroquial que hizo al pueblo el Arzobispo de Lirna, Santc Toribio de Mogrovejo. Este documento también está en el Archivo Arzabispal do Lima. Indica estos datos: 
Tupi (5 leguas de Pampas). año 1002. Tributarios 80

reservados $\quad 16$

solteros (as)

viudos (as), 90

mujeres 60

muchachos (as) 137

Total 385 (sic) (1)

El Padrón actual de electores de lí Comunidad de Tupe en poder del personero indica 180 hombres mayores de edad.

La colonia de tupinos residentes en Lima, es de 58 hombres y 31 mujeres.

Ia lengua:

Los habitantes de Tupe son bilingues en su mayoría, hablan todos el castellano y el KAUKE o XAKARO. Nadie habla keshwa, ni aimará.

El idioma kauke se conserva puro enire las mujeres. Entre ellas hay algunas que no entienden el castellano o si lo entienden, no lo hablan.

Los niños $y$ niñas hablan el kauke primeramente y luego el castellano.

En Cachuy pocos son los que hablan el kauke y ellos han introducido algunas modificaciones y dan divers̄as tonalidades a la pronunciación. En muchas palabras o conversaciones los cachuinos no entienden a los de Tupe.

En la Puna se habla el kauke, ya que los dueños son de Tupe, pero existe un grupo de los alrededores que hablan el keshwa, siendo éste el único lugar donde se habla, en esta área.

En Aiza, Colca y Wanturo todos hablan kauke. En Catahuasi dos o tres personas, lo hablan.

Según referencias de los moradores de Tupe, este idioma ha sufrido algunas modificaciones y actualmente las personas de más edad y las mujeres sobre todo, conocen y hablan muchas palabras en kauke que no son entendidas por el resto.

(1) Es interesante el dalo que consigna esta visita sobre el viaje de los de Lunahuana y Chacaray para ser confirmados en Tupe en 1588. Esle Arzobispo visitó el pueblo de Tupe dos veces en 1588 y 1602. En 1588 confirmó a 337 personas y en 1602 a 104 . 
Es una lengua aglutinante. En su composición actual existen incorporadas muchas palabras keshwas y aimarás.

Actualmente Tupe es el único sitio del Perú donde se habla este ¿dioma. La investigación etnológiza que estamos realizando tiene entre sus principales ohjetivos presentar un panorama de la cultura de esta área lingüística y lograr que ella constituya la base para estudios científicos que lleguen a una conclusión del problema lingüístico del kauke en el Perú. El profesor J. M. B. Farfán de esta Universidad está realizando estudios de este idioma.

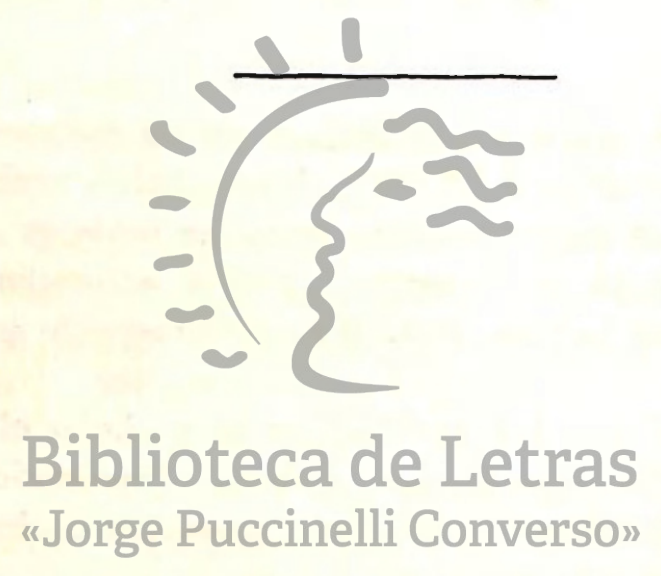

NOTA.-Debido a la zorencia ce signos iontícss para la impresión, se ha usado la escritura da los vocábios indígenas como estan regisiredos en la Comunidad de Tupe en sus múltiples documentos. En nuestras fichas usanios la troscripción fonética de la Universidad de Farís. 